\section{Metabolism of Apolipoprotein B in Large Triglyceride-rich Very Low Density Lipoproteins of Normal and Hypertriglyceridemic Subjects}

\author{
Christopher J. Packard, Avril Munro, A. Ross Lorimer, \\ Antonio M. Gotto, and James Shepherd \\ Departments of Biochemistry and Medical Cardiology, Royal \\ Infirmary, Glasgow G4 OSF, Scotland; and Division of \\ Atherosclerosis and Lipoprotein Research, Department of \\ Medicine, Baylor College of Medicine and The Methodist \\ Hospital, Houston, Texas 77030
}

bstract. The metabolic fate of very low density lipoprotein can be examined by following the transit of its apolipoprotein B moiety through the delipidation cascade, which leads to low density lipoprotein. In this study we have used cumulative flotation ultracentrifugation to follow the metabolism of various lipoprotein subclasses that participate in this process in normal, hypertriglyceridemic (Type IV), and dysbetalipoproteinemic (Type III) subjects. Large triglyceride-rich very low density lipoproteins of Svedberg units of flotation $\left(\mathbf{S}_{\mathrm{f}}\right)$ $100-400$ were converted virtually quantitatively in normal subjects to smaller $S_{\mathrm{f}}$ 12-100 remnant particles. Only a minor fraction appeared thereafter in low density lipoproteins $\left(\mathrm{S}_{\mathrm{f}} \mathrm{0}-12\right)$, most being removed directly from the plasma. Type IV hyperlipoproteinemic individuals converted the larger $S_{\mathrm{f}}$ 100-400 very low density lipoproteins to intermediate particles at $\sim 50 \%$ of the control rate but thereafter their metabolism was normal (fractional clearance of $S_{\mathrm{f}} 12-100$ particles in controls, $1.29 \pm 0.23$ pools/d; in Type IV hypertriglyceridemics, $1.38 \pm 0.23$ pools $/ \mathrm{d} ; n=4$ in each case). Since the apolipoprotein $B$ in large triglyceride-rich particles did not contribute significantly to the mass of the low density lipoprotein apoprotein pool, the latter must come largely from another source. This was examined by following the metabolic fate of small very low density lipoproteins of $S_{\mathrm{f}}$ 20-60 or of the total lipoprotein spectrum of $d$ $<1.006 \mathrm{~kg} /$ liter (approximate $\mathrm{S}_{\mathrm{f}} 20-400$ ). The small

Received for publication 3 February 1983 and in revised form 18 July 1984.

J. Clin. Invest.

(c) The American Society for Clinical Investigation, Inc. $0021-9738 / 84 / 12 / 2178 / 15 \quad \$ 1.00$

Volume 74, December 1984, 2178-2192 particles were rapidly and substantially converted to low density lipoproteins, suggesting that the major precursor of the latter was to be found in this density range. Whereas only $10 \%$ of apolipoprotein B in $S_{f} 100-400$ lipoproteins reached the low density lipoprotein flotation range, $>40 \%$ of $S_{f} 20-100$ B protein eventually appeared in $\mathrm{S}_{\mathrm{f}}$ 0-12 particles; and when very low density lipoprotein of $d<1.006 \mathrm{~kg} /$ liter is used as a tracer of apolipoprotein $\mathrm{B}$ metabolism it is primarily this population of small very low density lipoprotein particles in the $S_{\mathrm{f}} 12$ 100 flotation range that is labeled. A detailed examination was made of apolipoprotein B metabolism in three dysbetalipoproteinemic subjects. The plasma clearance curves of their $S_{f} 100-400$ lipoproteins were distinctly biphasic. The quickly decaying component converted rapidly into remnants of $S_{f} 20-60$ at a near normal rate ( 0.56 vs. $0.62 \mathrm{pools} / \mathrm{d}$ in normal subjects). Its subsequent processing, however, was retarded. The more slowly catabolized fraction, comprising $30 \%$ of the total apolipoprotein B radioactivity, had no counterpart in normal or Type IV hyperlipoproteinemic individuals. These data, taken together, suggest that the very low density lipoprotein consists of a complex mixture of particles with different origins and fates. Within the $S_{\mathrm{f}} 20-100$ flotation range there are at least two subcomponents. One represents remnants of larger triglyceride-rich particles which are catabolized slowly and feeds little apolipoprotein B into low density lipoprotein. The other is apparently secreted directly into this flotation interval and transfers significant amounts of $B$ protein rapidly into $\mathrm{S}_{\mathrm{f}}$ 0-12 lipoproteins.

\section{Introduction}

Although it is clear from physical and chemical evidence that human very low density and low density lipoproteins (VLDL 
and LDL) of Svedberg units of flotation $\left(S_{f}\right)^{1} \quad 0-400$ are heterogeneous, most investigations of their metabolism have, for the sake of simplicity, assumed homogeneity in one or both classes. Initial studies designed to examine the conversion of total VLDL $(d<1.006 \mathrm{~kg} /$ liter $)$ to LDL $(d<1.006-1.063$ $\mathrm{kg} /$ liter) suggested that, at least in normal subjects, there exists a precursor-product relationship between the two (1). Recent attempts to subfractionate these species have revealed new levels of complexity in this metabolic scheme (2-4). In particular, it is now apparent that there is another class of lipoproteins $(5,6)$, commonly termed intermediate density lipoprotein $(d=1.006-1.019 \mathrm{~kg} /$ liter $)$ with a nominal $S_{\mathrm{f}}$ value of 12-20, which constitutes an identifiable though transient metabolic intermediate between VLDL and LDL. This appreciation has led to the observation that not all apolipoprotein B (apoB) in VLDL subsequently appears in the LDL density range, even in normal subjects (6). In hypertriglyceridemic individuals the situation appears to be more complex still, inasmuch as their LDL is clearly polydisperse both in terms of structure and metabolism (4).

Several approaches have been made to examine the physicochemical heterogeneity of VLDL. Early chromatographic studies using an agarose gel matrix (7) demonstrated that this class has a particle size range of $\sim 300-1,000 \AA$. With decreasing size, the triglyceride content of the particle falls and it becomes relatively enriched in cholesterol and protein, giving rise at the lower end of the spectrum to VLDL with features similar to those of the remnant particles derived by lipolysis of very large intestinal triglyceride-rich chylomicrons (8). Cumulative flotation ultracentrifugation provides a convenient method for subfractionating VLDL into particles of defined flotation rate (9). Although the separation here depends primarily on particle density, the resulting fractions are similar to those obtained by agarose gel filtration. Thus, when compared with the largest particles $\left(S_{f} 100-400\right)$, the smaller species $\left(S_{f} 20-60\right)$ are enriched in protein and cholesteryl esters and depleted of triglyceride $(10,11)$. In a preliminary study $(12)$ we have used the cumulative flotation procedure to show that the large VLDL of $S_{f} 100-400$ is converted stepwise to particles of $S_{f}$ 20-60, which thereafter transfer to some extent into denser lipoproteins; other workers have usefully employed the technique to demonstrate that both triglyceride and apoB can enter the pathway at several points along its length. For example, Fisher et al. (4) have found that $25-60 \%$ of the newly synthesized apoB first appears in the cascade at the level of the small, triglyceride-depleted particle.

In the present study we have examined the metabolic heterogeneity of VLDL in greater detail and have compared our results acquired by the cumulative flotation procedure

1. Abbreviations used in this paper: apoB, apolipoprotein B; Dys $\beta$ HTG, and N, designate dysbetalipoproteinemic, hypertriglyceridemic, and normal subjects, respectively; $S_{f}$, Svedberg units of flotation, negative sedimentation coefficient at $d=1.063 \mathrm{~kg} /$ liter and $26^{\circ} \mathrm{C}$. with those obtained by conventional anglehead ultracentrifugation. Our approach was to label large, triglyceride-rich VLDL and follow the metabolic fate of its apoB moiety in control and hypertriglyceridemic individuals. Our findings suggest that this VLDL particle does not make a major contribution to LDL production, which derives instead primarily from particle synthesis into the smaller, denser VLDL range.

\section{Methods}

Subjects. Nine control and eight hypertriglyceridemic subjects gave informed consent for the study. Their plasma lipid and lipoprotein profiles, measured according to the protocol described in the Lipid Research Clinics Manual of Laboratory Operations (13), are presented in Table I. None showed clinical or biochemical evidence of renal, hepatic, endocrine, or hematologic dysfunction, and all drug therapy known to affect lipid metabolism was withdrawn at least 1 mo before the study. Potassium iodide was prescribed at a dose of $60 \mathrm{mg}$ three times a day for $3 \mathrm{~d}$ before and $1 \mathrm{mo}$ after administration of radioiodinated lipoproteins. The study protocol conformed to the requirements of the Human Research Committees of Glasgow Royal Infirmary and The Methodist Hospital, Houston, TX.

Experimental protocol. The study was designed to examine the metabolism of apoB in its transit from large $\left(S_{\mathrm{f}} 100-400\right)^{2}$ triglyceriderich VLDL through to LDL $\left(S_{\mathrm{f}} 0-12\right)$. The control subjects were examined in three groups (A-C, Table I). Four volunteers in group A received an intravenous injection of ${ }^{125} \mathrm{I}-\mathrm{VLDL}\left(\mathrm{S}_{\mathrm{f}} 100-400\right)$; three in group B were given the same material plus a tracer dose of ${ }^{131} \mathrm{I}-\mathrm{VLDL}$ $(d<1.006 \mathrm{~kg} /$ liter $) ;{ }^{2}$ and two in group $\mathrm{C}$ received intravenous injections of ${ }^{125} \mathrm{I}-\mathrm{VLDL}\left(\mathrm{S}_{\mathrm{f}} 40-60\right)$ and ${ }^{131} \mathrm{I}-\mathrm{VLDL}\left(\mathrm{S}_{\mathrm{f}} 20-40\right)$ in an attempt to define the events that take place in this narrow density interval. The eight hypertriglyceridemic subjects were studied in two groups. The first of these comprised four Type IV individuals (Table I) who were examined with four control subjects and received a tracer of autologous ${ }^{125} \mathrm{I}-\mathrm{VLDL}\left(\mathrm{S}_{\mathrm{f}} 100-400\right)$. The same lipoprotein fraction was injected into the second group (group D, Table I) of three Type III and one Type IV hyperlipoproteinemic patients. Simultaneously, two of the former and the Type IV individual were given autologous $S_{\mathrm{f}} 20-60$ VLDL while the other Type III volunteer received homologous $S_{\mathrm{f}} 100$ 400 VLDL from the Type IV subject.

Lipoprotein isolation techniques. All lipoprotein isolations were performed by cumulative flotation ultracentrifugation except in experiment $B$ where, in addition, fractions were separated by a fixed angle technique (14) using a Beckman $\mathbf{4 0 . 3}$ rotor (Beckman Instruments Inc., Fullerton, CA). In their definitive paper on the subject, Lindgren et al. (9) described two discontinuous gradient separation systems. The first (system I), designed to fractionate lipoproteins of $S_{\mathrm{f}}>20$, was based on a $\mathrm{NaBr}$ gradient whose density ranged from 1.0464 to 1.006 $\mathrm{kg} /$ liter. In the second system, the gradient was constructed from $d$ $=1.0988$ to $1.0588 \mathrm{~kg} /$ liter, permitting separation of lipoproteins of $\mathrm{S}_{\mathrm{f}}$ $>0$. By use of both of these gradients, VLDL and LDL fractions of defined flotation rate could be selected at will by variation of the

2. Throughout the paper we have adopted the convention that $S_{f}$ values denote lipoprotein fractions prepared by cumulative flotation. Where density intervals (e.g., $d<1.006 \mathrm{~kg} /$ liter) are quoted these refer to fractions prepared by anglehead ultracentrifugation. 
Table I. Plasma Lipid and Lipoprotein Values for Nine Control and Eight Hyperlipoproteinemic Subjects

\begin{tabular}{|c|c|c|c|c|c|c|c|c|c|}
\hline \multirow[b]{2}{*}{$\begin{array}{l}\text { Experi- } \\
\text { ment }\end{array}$} & \multirow[b]{2}{*}{ Tracer injected } & \multirow[b]{2}{*}{ Subject (sex) } & \multirow[b]{2}{*}{ Age } & \multirow[b]{2}{*}{$\begin{array}{l}\text { Body } \\
\text { weight }\end{array}$} & \multirow[b]{2}{*}{$\begin{array}{l}\text { Plasma } \\
\text { triglyceride }\end{array}$} & \multirow[b]{2}{*}{$\begin{array}{l}\text { Plasma } \\
\text { cholesterol }\end{array}$} & \multicolumn{3}{|c|}{ Cholesterol (mmol/liter) } \\
\hline & & & & & & & In VLDL & In LDL & In $\mathrm{HDL}$ \\
\hline & & & $y r$ & kg & $\mathrm{mmol} / \mathrm{liter}$ & $\mathrm{mmol} / \mathrm{liter}$ & & & \\
\hline \multirow[t]{8}{*}{$\mathbf{A}$} & ${ }^{125} \mathrm{I}-\mathrm{VLDL}$ & $N_{1}(M)$ & 27 & 68 & 2.25 & 5.55 & 0.90 & 3.55 & 1.10 \\
\hline & (Sf 100-400) & $\mathrm{N}_{2}(\mathrm{M})$ & 23 & 76 & 1.20 & 6.60 & 0.20 & 4.10 & 2.20 \\
\hline & & $\mathrm{N}_{3}(\mathrm{~F})$ & 48 & 50 & 1.90 & 5.55 & 0.70 & 3.70 & 1.20 \\
\hline & & $\mathrm{N}_{4}(\mathrm{M})$ & 36 & 62 & 1.95 & 5.80 & 0.75 & 3.25 & 2.10 \\
\hline & & $\mathrm{HTG}_{1}(\mathrm{~F})$ & 57 & 57 & 5.48 & 8.03 & 2.84 & 4.10 & 1.09 \\
\hline & & $\mathrm{HTG}_{2}(\mathrm{M})$ & 52 & 79 & 13.72 & 8.53 & 4.42 & 3.05 & 0.94 \\
\hline & & $\mathrm{HTG}_{3}(\mathrm{M})$ & 64 & 69 & 8.54 & 6.97 & 3.10 & 2.92 & 0.96 \\
\hline & & $\mathrm{HTG}_{4}(\mathrm{M})$ & 46 & 70 & 5.31 & 5.19 & 1.50 & 3.10 & 0.99 \\
\hline \multirow[t]{3}{*}{ B } & $\begin{array}{l}{ }^{125} \text { I-VLDL } \\
\left(\mathrm{S}_{\mathrm{f}} 100-400\right)\end{array}$ & $\mathrm{N}_{5}(\mathrm{~F})$ & 23 & 40 & 0.81 & 4.83 & 0.23 & 3.03 & 1.59 \\
\hline & 131I-VLDL & $\mathrm{N}_{6}(\mathrm{M})$ & 22 & 76 & 1.15 & 4.75 & 0.50 & 2.65 & 1.60 \\
\hline & $(d<1.006 \mathrm{~kg} /$ liter $)$ & $\mathbf{N}_{7}(\mathbf{M})$ & 25 & 81 & 1.80 & 6.50 & 0.75 & 4.60 & 1.10 \\
\hline \multirow[t]{3}{*}{ C } & ${ }^{131}$ I-VLDL & & & & & & & & \\
\hline & $\left(S_{f} 40-60\right)$ & $\mathbf{N}_{8}(\mathrm{M})$ & 27 & 77 & 1.70 & 4.00 & 0.65 & 2.00 & 1.30 \\
\hline & $\begin{array}{l}{ }^{125} \mathrm{I}-\mathrm{VLDL} \\
\left(\mathrm{S}_{\mathrm{f}} 20-40\right)\end{array}$ & $\mathbf{N}_{9}(\mathbf{M})$ & 24 & 62 & 1.10 & 3.60 & 0.60 & 1.75 & 1.25 \\
\hline \multirow[t]{5}{*}{ D } & ${ }^{125} \mathrm{I}-\mathrm{VLDL}$ & & & & & & & & \\
\hline & $\left(S_{f} 100-400\right)$ & $\operatorname{Dys}_{\beta_{1}}(\mathrm{M})$ & 61 & 69 & 3.43 & 8.23 & 3.61 & 3.84 & 0.76 \\
\hline & $\begin{array}{l}{ }^{131} \mathrm{I}-\mathrm{VLDL} \\
\left(\mathrm{S}_{\mathrm{f}} 20-60\right)\end{array}$ & Dys $\beta_{2}(M)$ & 60 & 76 & 5.05 & 9.74 & 5.83 & 3.17 & 0.75 \\
\hline & $\begin{array}{l}{ }^{13 !} \text { I-VLDL from Dys } \beta_{3} \\
\left(S_{\mathrm{f}} 100-400\right) \\
{ }^{125} \mathrm{I}_{-V L D L} \text { from HTG } \\
\left(\mathbf{S}_{\mathrm{f}} 100-400\right)\end{array}$ & Dys $\beta_{3}(M)$ & 49 & 73 & 2.41 & 6.80 & 1.81 & 4.11 & 1.11 \\
\hline & $\left.\begin{array}{c}{ }^{125} \mathrm{I}-\mathrm{VLDL} \\
\left(\mathrm{S}_{\mathrm{f}} 100-400\right) \\
{ }^{131} \mathrm{I}-\mathrm{VLDL} \\
\left(\mathrm{S}_{\mathrm{f}} 20-60\right)\end{array}\right\}$ & $\mathrm{HTG}_{5}(\mathrm{M})$ & 52 & 63 & 6.63 & 8.22 & 2.98 & 4.37 & 0.87 \\
\hline
\end{tabular}

centrifugal force applied to the sample, which thereby facilitated examination of different lipoprotein subfractions within the spectrum. The conditions employed in the separation of VLDL of $S_{\mathrm{f}} 100-400$, $60-100$, and $20-60$ by system I and lipoproteins of $S_{f} 12-20,6-12$, and $0-6$ by system II have been detailed elsewhere by Lindgren and his colleagues (9). In addition, we have modified the centrifugal conditions to permit preparation of lipoprotein fractions of $S_{\mathrm{f}} 20-40$ and 40-60 (by system I) and $S_{\mathrm{r}} 100-400,12-100$, and 0-12 (by system II). The former were isolated by the initial application of a force of $2.10 \times 10^{11} \mathrm{rad}^{2} \cdot \mathrm{s}^{-1}$ (i.e., $39,000 \mathrm{rpm}$ for $210 \mathrm{~min}$ in a Beckman SW 40 rotor [Beckman Instruments Inc.], $23^{\circ} \mathrm{C}$ ). $S_{f}>60$ lipoproteins were removed in the top $0.5 \mathrm{ml}$ of tube contents. Two further centrifugations, applying sequential forces of $2.02 \times 10^{11} \mathrm{rad}^{2} \cdot \mathrm{s}^{-1}(39,000 \mathrm{rpm}, 202$ $\left.\min , 23^{\circ} \mathrm{C}\right)$ and $6.52 \times 10^{11} \mathrm{rad}^{2} \cdot \mathrm{s}^{-1}\left(32,800 \mathrm{rpm}, 920 \mathrm{~min}, 23^{\circ} \mathrm{C}\right)$ yielded in the top $0.5 \mathrm{ml}$ of the tube VLDL of $S_{\mathrm{f}} 40-60$ and $20-40$, respectively. System II was modified as follows to subfractionate $S_{\mathrm{f}} 0$
400 lipoproteins into the three fractions specified above. The first centrifugation, at $37,000 \mathrm{rpm}$ for $66 \mathrm{~min}\left(23^{\circ} \mathrm{C}\right)$ in the $S W 40$ rotor $\left(5.95 \times 10^{10} \mathrm{rad}^{2} \cdot \mathrm{s}^{-1}\right)$ gave VLDL of $\mathrm{S}_{\mathrm{f}} 100-400$ in the top $1.0 \mathrm{ml}$ of the gradient. This was removed by careful aspiration and replaced with $1.0 \mathrm{ml}$ of $1.0588 \mathrm{~kg} /$ liter $\mathrm{NaBr}$ solution. Recentrifugation for 1,056 min at $27,000 \mathrm{rpm}\left(5.07 \times 10^{11} \mathrm{rad}^{2} \cdot \mathrm{s}^{-1}, 23^{\circ} \mathrm{C}\right)$ yielded lipoproteins of $\mathrm{S}_{\mathrm{f}} 12-100$ in the top $0.5 \mathrm{ml}$ of the gradient; a final centrifugation at $28,000 \mathrm{rpm}$ for $1,272\left(6.5 \mathrm{~min} \times 10^{11} \mathrm{rad}^{2} \cdot \mathrm{s}^{-1}, 23^{\circ} \mathrm{C}\right)$ gave LDL $\left(\mathrm{S}_{\mathrm{f}}\right.$ $0-12$ ) in the top $0.5 \mathrm{ml}$. In order to prepare an adequate amount of VLDL $\left(S_{\mathrm{f}} 100-400\right)$ for injection into the normal subjects it was necessary to make an initial VLDL concentrate $\left(d<1.006 \mathrm{~kg} /\right.$ liter, $S_{\mathrm{f}}$ $\sim 20-400$ ) from $200 \mathrm{ml}$ of their plasma by subjecting it to ultracentrifugation for $18 \mathrm{~h}\left(23^{\circ}\right)$ at $40,000 \mathrm{rpm}$ in a Beckman Ti 60 rotor (Beckman Instruments Inc.) (14). This crude preparation was then treated as described for plasma to isolate VLDL of $S_{\mathbf{f}} 100-400$. Where chylomicrons were present (i.e., in the Type III hyperlipoproteinemic 
subjects) they were removed from the plasma by preliminary centrifugation at $10,000 \mathrm{rpm}$ for $30 \mathrm{~min}\left(23^{\circ} \mathrm{C}\right)$ in a 40.3 rotor.

In experiment $\mathrm{B}$ we compared the metabolism of lipoprotein fractions isolated by cumulative flotation with that of conventional preparations made in an anglehead rotor. In the latter procedure (14) VLDL was prepared from the plasma of the fasting subjects by flotation at $d<1.006 \mathrm{~kg} /$ liter $\left(40,000 \mathrm{rpm}, 18 \mathrm{~h}, 23^{\circ} \mathrm{C}\right.$ in a $\mathrm{Ti} 60$ rotor) and concentrated and washed by a further centrifugation at that density. After radiolabeling and injection into the donor as described below, 4.0-ml aliquots of the subject's plasma collected at various intervals were overlayered with $2.0 \mathrm{ml}$ of $0.15 \mathrm{M} \mathrm{NaCl} / 0.01 \% \mathrm{Na}_{2}$ EDTA in a 40.3 rotor tube and subjected to centrifugation for $18 \mathrm{~h}$ at $39,000 \mathrm{rpm}$ $\left(23^{\circ} \mathrm{C}\right)$. VLDL $(d<1.006 \mathrm{~kg} / \mathrm{liter})$ was removed in the top $1.0 \mathrm{ml}$ of the tube. The next milliliter, which contained $<4 \%$ of the total sample radioactivity, was discarded, and the remaining $4.0 \mathrm{ml}$ was adjusted to $d=1.019 \mathrm{~kg} /$ liter by the addition of $0.48 \mathrm{ml}$ of $1.182 \mathrm{~kg} /$ liter $\mathrm{NaBr}$ solution and overlayered to $6.0 \mathrm{ml}$ with $1.019 \mathrm{~kg} /$ liter density $\mathrm{NaBr}$ solution. Recentrifugation for $18 \mathrm{~h}$ at $39,000 \mathrm{rpm}\left(23^{\circ} \mathrm{C}\right)$ yielded lipoproteins of $d=1.006-1.019 \mathrm{~kg} /$ liter in the top $1.0 \mathrm{ml}$ of the tube. This was again removed carefully by aspiration, the next milliliter was discarded, and the lower $4.0 \mathrm{ml}$ was increased in density and volume to $1.063 \mathrm{~kg} /$ liter and $6.0 \mathrm{ml}$ by the addition of $2.0 \mathrm{ml}$ of $1.151 \mathrm{~kg} /$ liter density solution. LDL $(d=1.019-1.063 \mathrm{~kg} / \mathrm{liter})$ was collected in the top $1.0 \mathrm{ml}$ of the tube after centrifugation for $24 \mathrm{~h}$ at $39,000 \mathrm{rpm}$ $\left(23^{\circ} \mathrm{C}\right)$.

Radioiodination of lipoproteins. Lipoproteins were radiolabeled by a modification (15) of the procedure of MacFarlane (16). The material was initially concentrated to a protein content of $1-5 \mathrm{mg} / \mathrm{ml}$ by pressure filtration (XM100 filters, Amicon Corp., Lexington, MA). Labeling efficiencies for VLDL $\left(\mathrm{S}_{\mathrm{f}} 100-400\right)$ and for lipoproteins of $d$ $<1.006 \mathrm{~kg} /$ liter or $\mathrm{S}_{\mathrm{f}} 20-60$ were typically $5-10$ and $10-20 \%$, respectively. The amount of $\mathrm{ICl}$ in the reaction mixture was therefore adjusted to incorporate no more than $1 \mathrm{~mol}$ of iodine/300,000 D of protein. Free iodide was removed from the labeled lipoprotein by gel filtration through a PD 10 column (Pharmacia Fine Chemicals, London) by use of $0.15 \mathrm{M} \mathrm{NaCl} / 0.01 \% \mathrm{Na}_{2}$ EDTA (pH 7.0) as eluant. Of the material that eluted in the column void volume, $>95 \%$ was precipitable with $10 \%$ trichloracetic acid. Less than $30 \%$ of the radioactivity in $S_{\mathrm{f}}$ $100-400$ VLDL and $15 \%$ in the denser lipoproteins could be extracted into chloroform/methanol (1:1, vol/vol). Approximately 40 and $70 \%$, respectively, of the remaining protein-bound radioactivity in these fractions was precipitable with $1,1,3,3$ tetramethylurea. Preliminary ultracentrifugation studies showed that the labeled lipoprotein preparations retained the ultracentrifugal characteristics of their parent lipoprotein in that $>90 \%$ of their radioactivity floated within the expected density interval.

Most apoB-associated radioactivity present in the $S_{\mathrm{f}} 100-400$ fraction comigrated upon polyacrylamide gel electrophoresis (17) with apoB 100 in LDL (Fig. 1). Less than 15\% appeared in the smaller molecular weight $B$ protein $\left(B_{48}\right)$ of chylomicrons.

Turnover protocol. All solutions used to isolate and prepare lipoprotein fractions for human administration were fresh and, where possible, sterilized by autoclaving.

After labeling was done the lipoproteins were filtered through 0.45 $\mu \mathrm{m}$ filters (Amicon Corp.). The participants received $\sim 50 \mu \mathrm{Ci}(0.1$ mg protein) of the appropriate tracer (see Table I) via an indwelling venous catheter. The injection was timed at 8:00 $\mathrm{AM}$ in all studies, and thereafter blood was collected frequently over the next $24 \mathrm{~h}$ and then daily, in the fasting state, for $14 \mathrm{~d}$. All subjects fasted for $14 \mathrm{~h}$ before sample injection, and on the first day of the study their fat

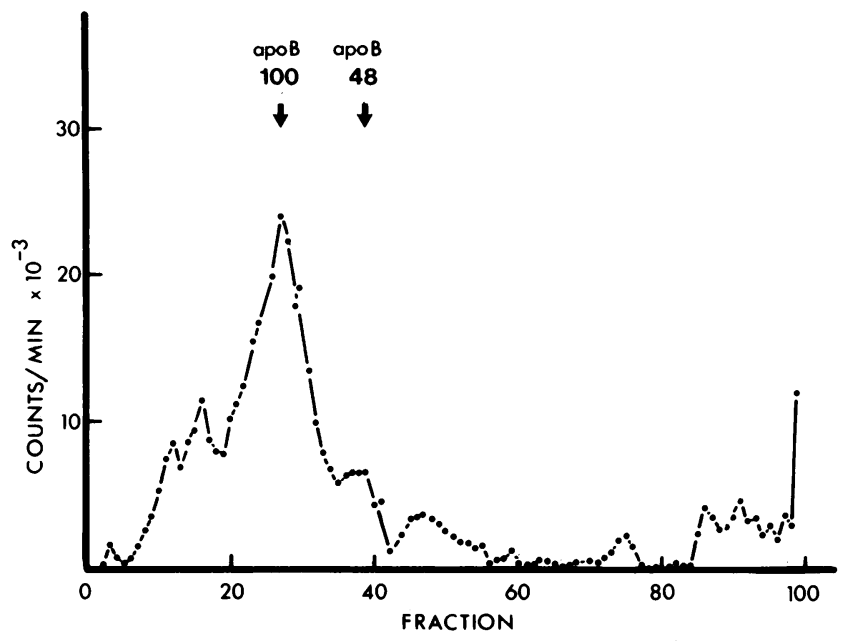

Figure 1. Profile of radioactive apoVLDL on $3 \%$ SDS polyacrylamide gels. ${ }^{125}$ I-VLDL $(d<1.006 \mathrm{~kg} /$ liter $)$, initially isolated from normal plasma, was lyophilized and delipidated with ether/ethanol, and its apoproteins were separated on SDS gels as described by Kane et al. (17). The arrows on the radioactivity profile indicate the positions of the B protein in LDL $\left(\mathrm{apoB}_{100}\right)$ and chylomicrons $\left(\mathrm{apoB}_{48}\right)$. Hypertriglyceridemic VLDL gave a similar profile.

intake was limited to $<5.0 \mathrm{~g}$ to minimize chylomicron production. At 6:00 PM they were given their first meal, and thereafter until midnight hourly snacks were supplied to provide the subject with his other regular dietary constituents (excluding fat) at their normal level. This nutritional procedure was gauged from a previously obtained 7-d weighed food record and was under the control of a dietitian.

Plasma aliquots, taken at each time point, were collected into $0.01 \% \mathrm{Na}_{2}$ EDTA and subjected to ultracentrifugation as described above to isolate the lipoprotein fractions appropriate to each experiment (see Table I). These were stored at $4^{\circ} \mathrm{C}$ until the end of the collection period. The apoB present in each isolated fraction was then prepared by the tetramethylurea precipitation procedure of Kane et al. (10), conducted at a temperature of $37^{\circ} \mathrm{C}$. The coefficient of variation on replicate samples was $8-12 \%$ for VLDL, IDL, and LDL apoB. In selected studies, duplicate samples were analyzed by the above tetramethylurea procedure and in parallel by the isopropanol precipitation technique of Holmqvist, Carlson, and Carlson (18). The specific activity of the precipitated apoB did not differ significantly between the two. In the case of the normal subjects, whose VLDL $\left(S_{f} 100-400\right)$ concentration was low, it was necessary to add an equivalent amount of unlabeled carrier VLDL before tetramethylurea precipitation. Radioactivity and protein measurements were made on each isolated apoB fraction as detailed elsewhere (19). The pool size of apoB for any fraction was taken to be the mean recovered tetramethylurea precipitable protein. The apoB radioactivity in each fraction was expressed as a percentage of the total initial B protein activity found in the 10-min plasma sample. The plasma volume was calculated as $4 \%$ of the subjects' body weights, which gave values in good agreement with those obtained from the isotope dilution that occurred over the first $10 \mathrm{~min}$.

apoB kinetic analysis. The transfer of radioactivity from the labeled fraction to denser lipoprotein classes was analyzed by a computer- 


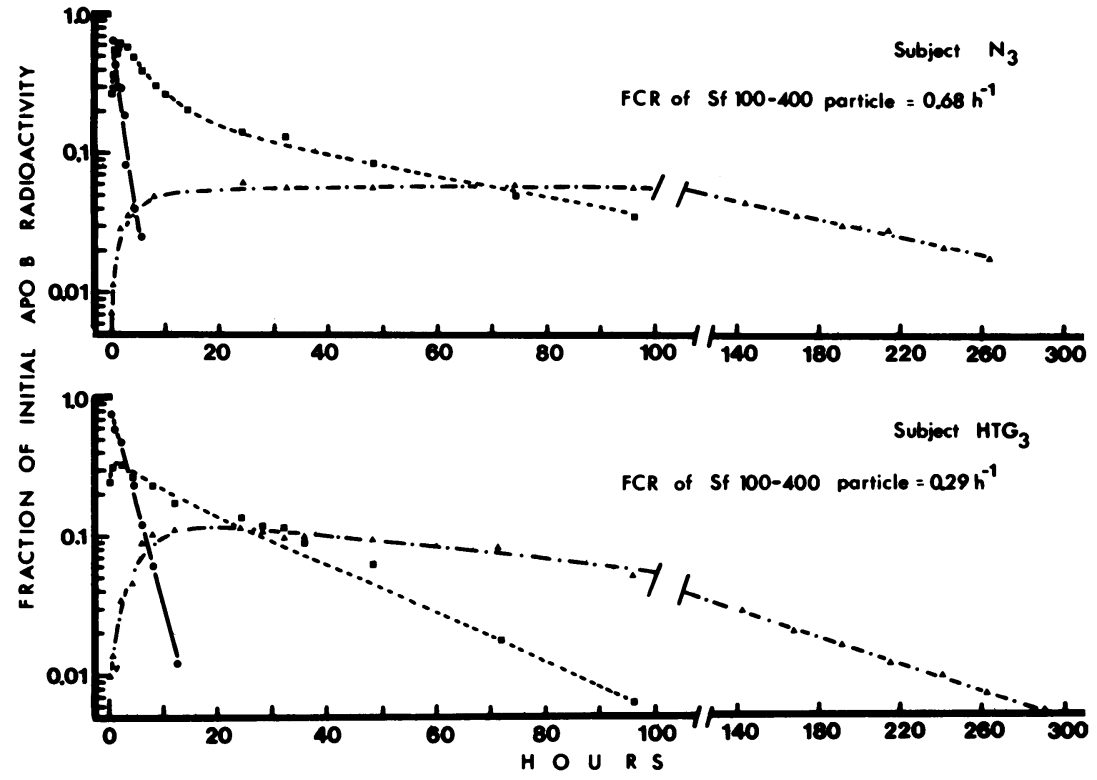

Figure 2. Transit of apoB radioactivity from VLDL, $S_{\mathrm{f}} 100-400,(\bullet)$ through an intermediate $S_{\mathrm{f}}$ 12-100 (๘) lipoprotein to $\mathrm{LDL}, \mathrm{S}_{\mathrm{f}} \mathbf{0 - 1 2}$, (A) in a normal $\left(\mathrm{N}_{3}\right)$ and a hypertriglyceridemic $\left(\mathrm{HTG}_{3}\right)$ subject. based multicompartmental modeling program. ${ }^{3}$ The algorithm used incorporated commercially available subroutines (Numerical Algorithms Group, Cambridge, England) into a simple Fortran program that permitted data input, model specification, and output of the parameters.

\section{Results}

Experiment $A$. This study examined the metabolic properties of $S_{\mathrm{f}}$ 100-400 VLDL apoB in normal and Type IV hyperlipoproteinemic subjects. Catabolism of an autologous ${ }^{125} \mathrm{I}$ labeled tracer of this fraction was followed through an intermediate of $S_{\mathrm{f}} 12-100$ to $\mathrm{LDL}\left(\mathrm{S}_{\mathrm{f}}\right.$ 0-12). Typical decay curves in a normal (subject $\mathrm{N}_{3}$ ) and a hypertriglyceridemic individual (subject $\mathrm{HTG}_{3}$ ) are presented in Fig. 2. These were analyzed by use of the multicompartmental model outlined in Fig. 3. ApoB radioactivity disappeared monoexponentially from the

3. Multicompartmental analysis was performed with a Fortran program similar to simulated analysis and modeling (SAAM) (29) and NONLIN (30). Three commercially available subroutines (Numerical Algorithms Group, Cambridge, England) were used to provide: $(a)$ integration of first order differential equations (DO2BBF); $(b)$ minimization of the sum of squared differences between observed and calculated values (EO4JAF); and (c) matrix inversion (FOIADF).

The algorithm proceeded as follows. The program input parameters were: ( $a$ ) time of sampling; $(b)$ observed apoB radioactivities expressed as a fraction of the total apoB radioactivity present in the 10-min sample; $(c)$ a weight for each datum calculated from its estimated error; and $(d)$ initial estimates for the rate parameters described in the models (Figs. 3, 4, and 8). An iterative procedure adjusted the rate constants to minimize the sum of squares between observed and calculated data. The final solution was accepted when it gave a consistent and unique fit to the data (31).
$S_{\mathrm{f}}$ 100-400 flotation range and accumulated rapidly in an $S_{\mathrm{f}}$ 12-100 species, which became maximally labeled within $\sim 5$ $h$. The biexponential clearance of activity from this intermediate fraction suggested that it contained at least two metabolically distinct components, reflected in the two pool system (pools 3 and 4, Fig. 3) which was required to achieve an acceptable computer fit of the data. The subsequent appearance of radioactivity in $\mathrm{S}_{\mathrm{f}}$ 0-12 lipoproteins, which increased progres-

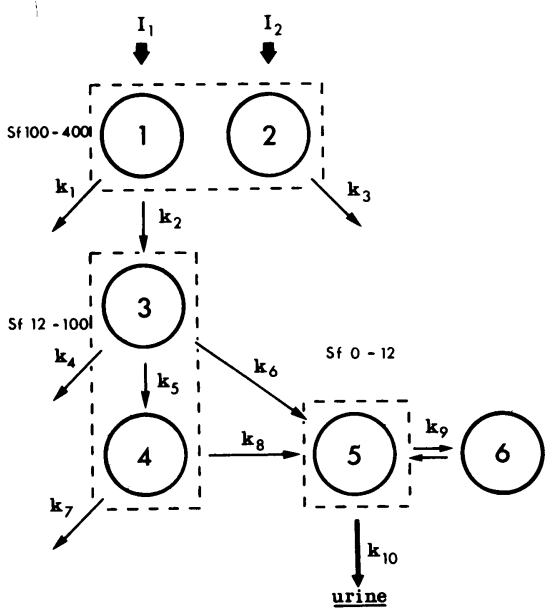

Figure 3. Multicompartmental model describing the transfer of apoB radioactivity from $S_{f} 100-400$ particles into the $S_{f} 0-12$ flotation range, which was used to analyze the plasma decay curves shown in Fig. 2. The fractional clearance rate of $S_{\mathbf{f}} 12-100$ apoB was calculated from the formula: $\mathrm{FCR}=\left[\left(k_{4} / k_{5}\right)\left(k_{7}+k_{8}\right)+\left(k_{6} / k_{5}\right)\left(k_{7}+k_{8}\right)+k_{7}\right.$ $\left.+k_{8}\right] /\left[1+\left(k_{7}+k_{8}\right) / k_{5}\right]$. 
sively for $24 \mathrm{~h}$ after the injection, indicated that at least a fraction of the apoB in the intermediate species was being transferred into LDL. The terminal clearance of LDL apoB radioactivity was slow (Fig. 2) and could be adequately represented by a single pool in equilibrium with an extravascular compartment (Fig. 3). The rates of exchange between these compartments was limited to maintain $72 \%$ of $\mathrm{LDL}$ in the plasma in accordance with values obtained from studies of LDL kinetics (see reference 20). Overall, the form of the plasma apoB clearance curves was similar in the normal and hypertriglyceridemic individuals. The rate constants that were derived from them by multicompartmental computer analysis are given in Table II. Transfer of apoB radioactivity from $S_{f}$ $100-400$ to $12-100$ lipoproteins was, as might be expected, slower in the hypertriglyceridemic group $\left(k_{2}\right.$ in the hypertriglyceridemics was $0.29 \pm 0.12 \mathrm{pools} / \mathrm{h}$ vs. $0.62 \pm 0.21 \mathrm{pools} / \mathrm{h}$ in the controls, $P<0.05$ ). Thereafter, however, the clearance of radioactivity from the intermediate $S_{\mathrm{f}} 12-100$ fraction was the same $(1.38 \pm 0.62$ pools/d in the hypertriglyceridemics vs. $1.29 \pm 0.23$ pools/d in the controls), as was the apoB decay from LDL (Table II). In most subjects the majority of apoB in $S_{\mathrm{f}}$ 100-400 lipoproteins was transferred to higher density fractions. However, two individuals $\left(\mathrm{N}_{2}\right.$ and $\left.\mathrm{HTG}_{3}\right)$ showed direct catabolism of about half of their $S_{f} 100-400$ apoB. The reason for this phenomenon is not clear. Since the apoB pool in the $S_{\mathrm{f}} 100-400$ interval of the normal subjects was very small, it could not be measured accurately. It was necessary to add unlabeled carrier VLDL (see Methods) to achieve recovery of the radioactivity in the B protein. Subtraction of the amount of carrier added from the total protein measured gave a maximum estimate of $S_{\mathrm{f}} 100-400$ VLDL apoB in the controls of $1.1 \mathrm{mg} / \mathrm{dl}$ (range $0.8-1.4 \mathrm{mg} / \mathrm{dl}$ ). Flux rates of the protein from this fraction are therefore not available for the normal subjects to provide a comparison with the values obtained in the hypertriglyceridemic group (see reference 20 ).
The mean plasma concentrations of apoB in $\mathrm{S}_{\mathrm{f}} 12-100$ and $0-12$ fractions in these four controls were $17 \pm 5.1$ and $64 \pm 10$ $\mathrm{mg} / \mathrm{dl}$, respectively.

One notable observation that emerged from this study was the slow clearance of apoB-associated radioactivity from the $S_{\mathrm{f}}$ 12-100 flotation range and its incomplete transfer into lipoproteins of $S_{f} 0-12$. This particular feature warranted further investigation and became the subject of the studies outlined below.

Experiment $B$. The results of experiment A differ substantially from observations that we and others had made about VLDL apoB metabolism by use of conventional ultracentrifugal separation procedures in anglehead rotors. We therefore proceeded to compare the fate of ${ }^{131} \mathrm{I}-\mathrm{VLDL}(d<1.006 \mathrm{~kg} / \mathrm{liter})$ prepared in a standard fixed anglehead rotor with that of ${ }^{125} \mathrm{I}$ VLDL $\left(S_{\mathrm{f}} 100-400\right)$ isolated by cumulative flotation. After the injection of these autologous tracers into the bloodstream of three normal subjects, lipoprotein fractions were isolated by both cumulative flotation and anglehead separation at limit densities of 1.006, 1.019, and $1.063 \mathrm{~kg} /$ liter. Representative anglehead-derived decay profiles and the kinetic parameters derived by use of the models shown in Figs. 3 and 4 are presented in Fig. 5 and Tables III and IV. Fig. $5 a$ shows that apoB radioactivity in the injected $S_{f} 100-400$ tracer was transferred only partially to the $d=1.006-1.019 \mathrm{~kg} /$ liter fraction and from there to LDL. Indeed, the peak value for LDL ( $\sim 8-9 \%$ of the initial plasma apoB radioactivity) in these three individuals was on a similar order to that found in the $\mathrm{S}_{\mathrm{f}} 0-12$ fraction of the control subjects $(\sim 6 \%)$ in experiment A. Conversely, the apoB injected in VLDL of $d<1.006 \mathrm{~kg} /$ liter, which had been prepared by anglehead centrifugation, was rapidly and substantially transferred through the $d=1.006-$ $1.019 \mathrm{~kg} /$ liter intermediate fraction to LDL (Fig. 5 b). Table IV describes the net transfer of radioactivity into LDL as a percentage of that initially associated with VLDL apoB. It can

Table II. Experiment A. Metabolism of $S_{f} 100-400$ VLDL apoB in Normal and Hypertriglyceridemic Subjects

\begin{tabular}{|c|c|c|c|c|c|c|c|c|c|c|c|c|}
\hline \multirow{3}{*}{$\begin{array}{l}\text { Sub- } \\
\text { ject }\end{array}$} & \multirow{2}{*}{\multicolumn{9}{|c|}{ Rate constants $\left(\mathrm{h}^{-1}\right)$}} & \multicolumn{3}{|c|}{ Fractional catabolic rate $\left(d^{-1}\right)$} \\
\hline & & & & & & & & & & \multirow{2}{*}{$\begin{array}{l}\text { VLDL } \\
\text { apoB }\end{array}$} & \multirow{2}{*}{$\begin{array}{l}S_{r} 12-100 \\
\text { apoB }\end{array}$} & \multirow{2}{*}{$\begin{array}{l}\text { LDL } \\
\text { apoB }\end{array}$} \\
\hline & $k_{1}$ & $k_{2}$ & $k_{3}$ & $k_{4}$ & $k_{3}$ & $k_{6}$ & $k_{7}$ & $k_{\mathrm{z}}$ & $k_{10}$ & & & \\
\hline $\mathbf{N}_{1}$ & 0 & 0.47 & 0 & 0.095 & 0.055 & 0 & 0 & 0.026 & 0.017 & 11.4 & 1.15 & 0.40 \\
\hline $\mathbf{N}_{2}$ & 1.15 & 0.94 & 0 & 0.21 & 0.12 & 0 & 0.014 & 0.009 & 0.012 & 50.0 & 1.25 & 0.28 \\
\hline $\mathrm{N}_{3}$ & 0 & 0.68 & 0 & 0.22 & 0.077 & 0.017 & 0.014 & 0.009 & 0.011 & 16.4 & 1.67 & 0.26 \\
\hline $\mathrm{N}_{4}$ & 0 & 0.40 & 0 & 0.12 & 0.026 & 0.004 & 0.0014 & 0.01 & 0.017 & 9.6 & 1.08 & 0.40 \\
\hline $\mathbf{H T G}_{1}$ & 0 & 0.31 & 0 & 0.046 & 0.035 & 0.019 & 0.022 & 0 & 0.014 & 7.5 & 0.92 & 0.34 \\
\hline $\mathbf{H T G}_{2}$ & 0 & 0.13 & 0.012 & 0.11 & 0.075 & 0 & 0.012 & 0.011 & 0.015 & 3.2 & 1.01 & 0.37 \\
\hline $\mathrm{HTG}_{3}$ & 0.43 & 0.46 & 0 & 0.17 & 0.15 & 0 & 0.01 & 0.016 & 0.018 & 21.4 & 1.12 & 0.43 \\
\hline $\mathrm{HTG}_{4}$ & 0.043 & 0.26 & 0 & 0.33 & 0.10 & 0.05 & 0.008 & 0.02 & 0.017 & 7.2 & 2.45 & 0.41 \\
\hline \multicolumn{10}{|c|}{ Mean, normal ( \pm 1 SD) } & $21.9 \pm 16.4$ & $1.29 \pm 0.23$ & $0.34 \pm 0.07$ \\
\hline \multicolumn{10}{|c|}{ Mean, HTG ( \pm 1 SD) } & $9.8 \pm 6.9$ & $1.38 \pm 0.62$ & $0.39 \pm 0.03$ \\
\hline
\end{tabular}




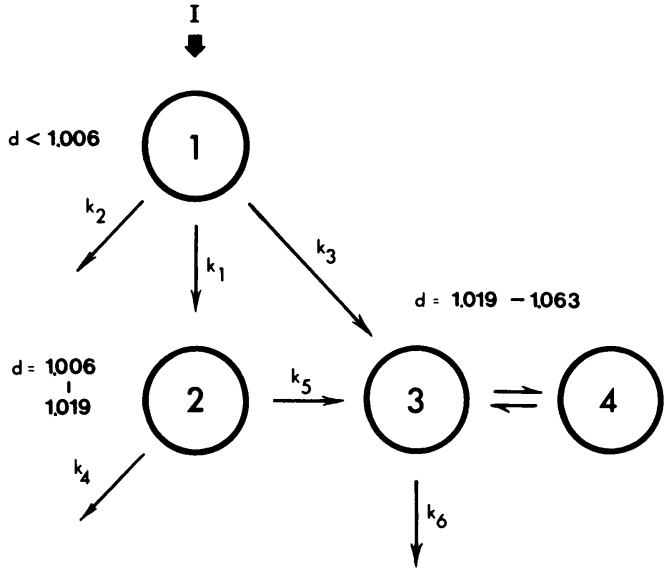

Figure 4. Multicompartmental model used to analyze the transfer of apoB radioactivity from VLDL $(d<1.006 \mathrm{~kg} /$ liter) through IDL ( $d$ $=1.006-1.019 \mathrm{~kg} /$ liter $)$ to $\mathrm{LDL}(d=1.019-1.063 \mathrm{~kg} /$ liter $)$.

be seen that when the anglehead rotor was used to prepare the VLDL tracer, $65-87 \%$ of the B protein radioactivity transferred from this $d<1.006 \mathrm{~kg} /$ liter fraction into lipoproteins of density 1.019-1.063 kg/liter. However, an $\mathrm{S}_{\mathrm{f}} 100-400$ VLDL tracer isolated by the cumulative flotation technique transmitted only $20-38 \%$ of its apoB activity from the $d<1.006 \mathrm{~kg} /$ liter density range into LDL of $d=1.019-1.063 \mathrm{~kg} / \mathrm{liter}$. This apparent inconsistency can be explained on the basis of the different particle population distributions that exist in the two VLDL preparations. Ultracentrifugal analysis of the tracers showed that, unlike the ${ }^{125} \mathrm{I} \mathrm{S}_{\mathrm{f}} 100-400$ VLDL, most radioactivity $\left(93,85\right.$, and $74 \%$, respectively, in subjects $\mathrm{N}_{5}, \mathrm{~N}_{6}$, and $\mathrm{N}_{7}$ ) in the ${ }^{131} \mathrm{I} d<1.006 \mathrm{~kg} /$ liter preparation was contained in small lipoproteins of $S_{f}<100$. These small particles cleared twice as fast into LDL (Table IV) than did lipoproteins of $S_{f}$ 20-100, which came from the metabolism of the ${ }^{125} I\left(S_{\mathrm{f}} 100-\right.$ 400) VLDL. The same pattern emerged when the plasma samples were subjected to cumulative flotation ultracentrifugation. Here, the mean peak values $( \pm 1 S D)$ in $S_{\mathrm{f}} 0-12$ lipoprotein were $4.1 \pm 2.6$ and $22.7 \pm 4.5 \%$ from the material of $S_{f}$ $100-400$ and $d<1.006 \mathrm{~kg} /$ liter, respectively.

Experiment $C$. The evidence from the above studies pointed to the likelihood of metabolic heterogeneity within VLDL of $\mathrm{S}_{\mathrm{f}}$ 20-100. We attempted to probe this by taking two narrow flotation intervals in this fraction and comparing their metabolism directly in two normal subjects. VLDL of $S_{\mathrm{f}} 20-40$ and 40-60 was prepared by cumulative flotation and labeled separately with ${ }^{125} \mathrm{I}$ and ${ }^{131} \mathrm{I}$, respectively. Their clearances from the $S_{\mathrm{f}}$ 12-100 fraction and appearances in $\mathrm{S}_{\mathrm{f}}$ 0-12 lipoproteins were then determined. Separate analyses were also made of $S_{f}$ 20-40 and 40-60 lipoproteins by use of a modified VLDL gradient (see Methods, system I). The composite results are presented in Fig. 6 and Table V. In each subject, the clearance of ${ }^{131} I$ radioactivity (originally in $S_{f} 40-60$ VLDL) from the $S_{f}$ 12-100 flotation range was slower, and its extent of conversion to $\mathrm{LDL}$ was less than that of ${ }^{125} \mathrm{I}$. We concluded that the $\mathrm{S}_{\mathrm{f}}$ 40-60 flotation interval contained some particles that decayed slowly and were not converted to LDL. The behavior of $S_{f}$ 20-40 material more closely resembled that population of particles labeled in VLDL of $d<1.006 \mathrm{~kg} /$ liter which had been prepared in the anglehead rotor (see experiment $B$ ). Note in Fig. 6 that the rate limiting step in the clearance of apoB from the $S_{\mathrm{f}} 12-100$ range must reside in particles of $S_{\mathrm{f}} 12-20$.

Experiment $D$. In light of these observations in normal subjects, we proceeded to examine VLDL apoB metabolism in four additional dyslipoproteinemic individuals, three of whom were classifiable as Type III on the basis of their VLDL cholesterol/plasma triglyceride ratio (21) and the presence in their plasma of a $\beta$ migrating VLDL fraction in the $d<1.006$ $\mathrm{kg} /$ liter density range. The dysbetalipoproteinemic subjects cleared apoB from their $S_{f}$ 100-400 VLDL biexponentially (Fig. $7 a$ ). The rapidly decaying component gave rise to the appearance of radioactivity in $S_{\mathrm{f}} 60-100$ and, subsequently, $S_{\mathrm{f}}$ 20-60 lipoproteins. The transition of apoB activity through this cascade was analyzed with the computer model shown in Fig. 8, which includes a compartment representing $\mathrm{S}_{\mathrm{f}}$ 0-12 lipoproteins for the sake of completeness, although the transmission of radioactivity into this fraction was too low to permit accurate quantitation. The derived rate constants describing the flow are presented in Table VI. The rapidly decaying component in the $S_{\mathrm{f}} 100-400$ flotation range has a fractional clearance rate (mean, 0.54 pools/h) that approached that of $S_{f} 100-400$ VLDL apoB in normal subjects. It was faster than the mean value observed for that fraction in the Type IV individuals (Fig. 2 and Table II). However, the slowly decaying component, which accounted for 33,39 , and $15 \%$ of the injected material (in dysbetalipoproteinemic subjects Dys $\beta$ 1,2 , and 3) had no counterpart either in the control or hypertriglyceridemic individuals and in fact was not present in homologous $S_{f} 100-400$ VLDL from subject $\mathrm{HTG}_{5}$ that was injected simultaneously with autologous VLDL into patients Dys $\beta_{3}$ (Fig. 7 c).

After its appearance in the $S_{\mathrm{f}}$ 20-60 flotation range, the radioactive apoB derived from $S_{\mathrm{f}} 100-400$ particles had a slow clearance rate. Its mean residence time in the three Type III subjects was 40,50 , and $56 \mathrm{~h}$. However, when in two of these subjects (Dys $\beta_{1}$ and Dys $\beta_{2}$ ) the lipoprotein in the $S_{\mathrm{f}} 20-60$ flotation range was isolated and labeled directly its metabolism differed from what is described above (Fig. 7 b). Specifically, the mean residence time of this material was significantly shorter (14 and $21 \mathrm{~h}$ for subjects Dys $\beta_{1}$ and Dys $\beta_{2}$, respectively) and its conversion to lipoproteins of a higher density $\left(S_{\mathbf{f}} 12-\right.$ 20) was more rapid (compare rate constants $k_{13}$ and $k_{12}$ in Table VI and Fig. 8). Nevertheless, it did include a slowly 


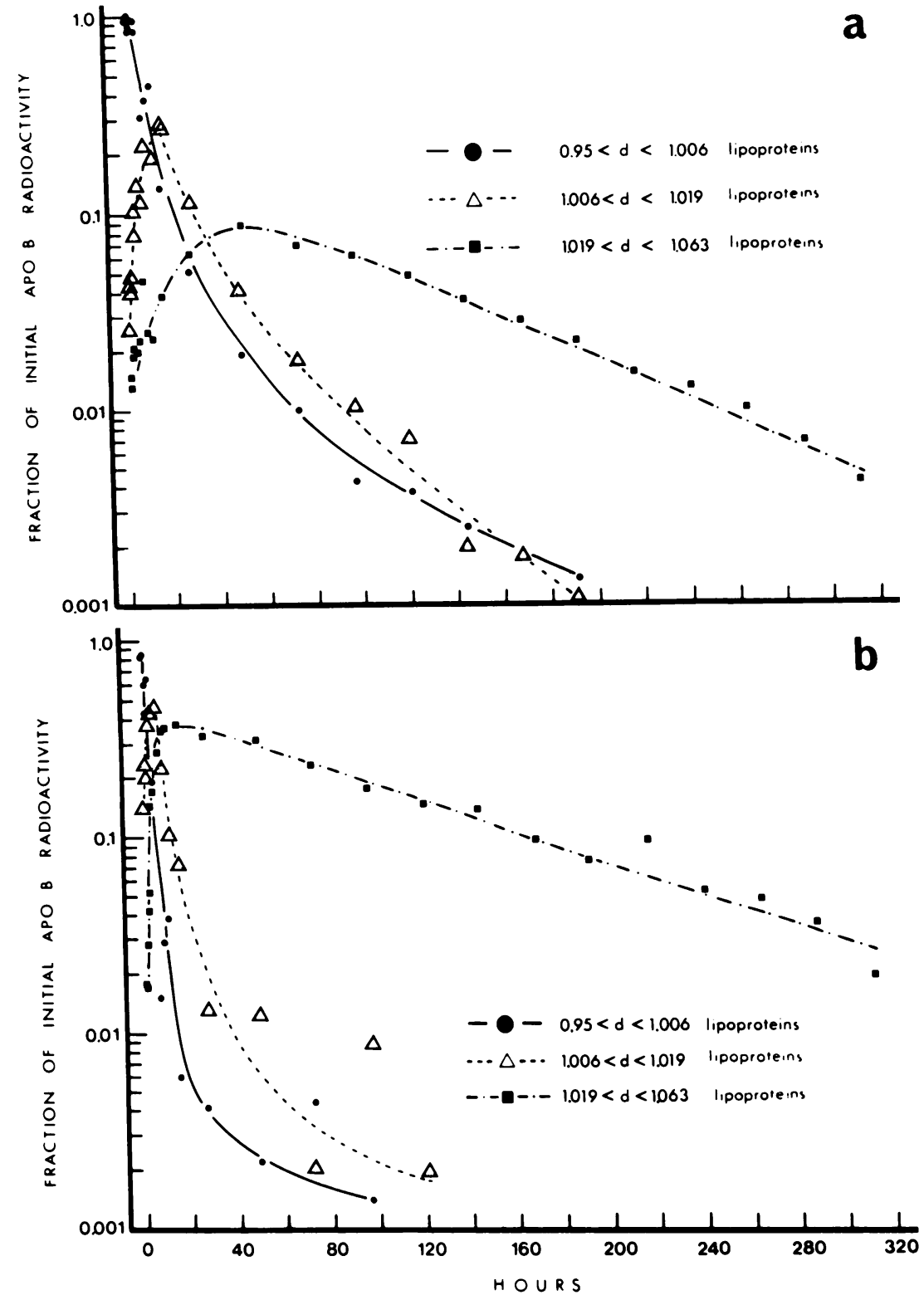

Figure 5. Decay profiles describing the flow of apoB radioactivity from VLDL into LDL. Two fractions of VLDL (of $d<1.006 \mathrm{~kg} /$ liter and $\mathrm{S}_{\mathrm{f}}$ 100-400) were prepared by anglehead and cumulative flotation ultracentrifugation and labeled with ${ }^{131} I$ and ${ }^{125}$ I, respectively. After reinjection into the donor $\left(\mathrm{N}_{6}\right)$ frequent plasma samples were collected over the next $14 \mathrm{~d}$ and used to isolate lipoproteins within the density ranges $d<1.006$, $d=1.006-1.019$, and $d=1.019-1.063 \mathrm{~kg} /$ liter. The radioactivities associated with these fractions are shown above. Panel $a$ describes the flow of activity after the injection of $S_{\mathrm{f}} 100-400 \mathrm{VLDL}$; in $b, d<1.006 \mathrm{~kg} /$ liter VLDL was injected. catabolized component with metabolic characteristics similar to those of material that had been derived from $S_{f} 100-400$ VLDL.

The kinetic parameters of apoB in VLDL of $S_{\mathrm{f}} 100-400$ and 20-60 for subject $\mathrm{HTG}_{5}$ are included for comparison (Table VI). The clearance rate of his $S_{f} 100-400$ apoB was similar to that observed in the other hypertriglyceridemic subjects. Again, the fractional catabolism of $S_{\mathrm{f}} 20-60$ VLDL apoB derived from $S_{f}$ 100-400 material was substantially slower than that of the directly labeled lipoprotein (compare 0.04 with 0.164 pools/h in Table VI). The plasma concentra- tions of apoB present in each flotation interval are provided for reference in Table VII. It is evident that in the dysbetalipoproteinemic subjects the apoB mass distribution favors the small $S_{\mathrm{f}}$ 20-60 VLDL fraction. A more complete comparison of the physical and chemical properties of these lipoprotein classes has been presented elsewhere (11).

\section{Discussion}

The apoB-containing lipoproteins VLDL and LDL, initially treated as structurally homogeneous entities, are now known 
Table III. Experiment B. Metabolism of $S_{f} 100-400$ and $d<1.006$ VLDL apoB in Three Normal Subjects

\begin{tabular}{|c|c|c|c|c|c|c|c|c|c|c|c|c|c|c|}
\hline \multirow[b]{2}{*}{$\begin{array}{l}\text { Experi- } \\
\text { ment }\end{array}$} & \multirow[b]{2}{*}{$\begin{array}{l}\text { Sub- } \\
\text { ject }\end{array}$} & \multirow[b]{2}{*}{ Tracer } & \multicolumn{9}{|c|}{ Rate constants $\left(h^{-1}\right)^{*}$} & \multicolumn{3}{|c|}{ Fractional catabolic rate $\left(d^{-1}\right)$} \\
\hline & & & $k_{1}$ & $k_{2}$ & $k_{3}$ & $k_{4}$ & $k_{\mathrm{s}}$ & $k_{6}$ & $k_{7}$ & $k_{8}$ & $k_{10}$ & $\begin{array}{l}S_{f} 100-400 \\
\text { apoB }\end{array}$ & $\begin{array}{l}\text { S, 12-100 } \\
\text { apoB }\end{array}$ & $\begin{array}{l}S_{f} 0-12 \\
\text { apoB }\end{array}$ \\
\hline \multirow[t]{6}{*}{ A } & $\mathrm{N}_{5}$ & $\begin{array}{l}{ }^{125} \mathrm{I}-\mathrm{VLDL} \\
\quad\left(\mathrm{S}_{\mathrm{f}} 100-400\right)\end{array}$ & 0.0 & 1.7 & 0.0 & 0.16 & 0.022 & 0.0 & 0.055 & 0.002 & 0.02 & 40.8 & 3.15 & 0.48 \\
\hline & $\mathrm{N}_{6}$ & $\begin{array}{l}{ }^{125} \mathrm{I}-\mathrm{VLDL} \\
\left(\mathrm{S}_{\mathrm{f}} 100-400\right)\end{array}$ & 0.0 & 0.67 & 0.0 & 0.16 & 0.063 & 0.005 & 0.0045 & 0.016 & 0.018 & 16.1 & 1.35 & 0.43 \\
\hline & $\mathrm{N}_{7}$ & $\begin{array}{l}{ }^{125} \mathrm{I}-\mathrm{VLDL} \\
\quad\left(\mathrm{S}_{\mathrm{f}} 100-400\right)\end{array}$ & 0.0 & 0.5 & 0.052 & 0.33 & 0.29 & 0.0 & 0.018 & 0.002 & 0.010 & 12.0 & 0.96 & 0.24 \\
\hline & & & & & & & & & & & \multicolumn{4}{|c|}{ Flux $(m g / k g$ per $d) \S$} \\
\hline & & & \multicolumn{6}{|c|}{ Rate constants $\left(h^{-1}\right) \ddagger$} & & & \multirow{2}{*}{$\begin{array}{l}\text { VLDL } \\
\text { apoB } \\
\text { catabolism }\end{array}$} & \multirow{2}{*}{$\begin{array}{l}\text { LDL apoB } \\
\text { synthesis }\end{array}$} & \multirow{2}{*}{\multicolumn{2}{|c|}{$\begin{array}{l}\text { LDL apoB } \\
(d=1.019-1.063 \\
\mathrm{kg} / \mathrm{liter}) \text { catabolism }\end{array}$}} \\
\hline & & & $k_{1}$ & $k_{2}$ & $k_{3}$ & $k_{4}$ & $k_{s}$ & $k_{6}$ & & & & & & \\
\hline \multirow[t]{3}{*}{ B } & $\mathbf{N}_{5}$ & $\begin{array}{l}{ }^{131} \mathrm{I}-\mathrm{VLDL} \\
\quad(d<1.006)\end{array}$ & 0.33 & 0.04 & 0.03 & 0.08 & 0.17 & 0.013 & & & 11.5 & 7.0 & 7.2 & \\
\hline & $\mathrm{N}_{6}$ & $\begin{array}{l}{ }^{131} \mathrm{I}-\mathrm{VLDL} \\
\quad(d<1.006)\end{array}$ & 0.40 & 0.0 & 0.031 & 0.3 & 0.48 & 0.018 & & & 16.6 & 10.2 & 8.6 & \\
\hline & $\mathrm{N}_{7}$ & $\begin{array}{l}{ }^{131} \mathrm{I}-\mathrm{VLDL} \\
\quad(d<1.006)\end{array}$ & 0.35 & 0.01 & 0.027 & 0.04 & 0.22 & 0.013 & & & 14.9 & 12.0 & 11.0 & \\
\hline
\end{tabular}

* These rate constants are defined in Fig. 3. $¥$ These rate constants are defined in Fig. 4. § Fluxes are calculated from the pool sizes and appropriate rate constants.

Table IV. Experiment B. Comparison of the Metabolism of $S_{f} 100-400$ and $d<1.006 \mathrm{~kg} / \mathrm{liter}$ VLDL apoB in Three Normal Subjects

\begin{tabular}{|c|c|c|c|c|c|}
\hline Subject & Tracer & $\begin{array}{l}\text { FCR of VLDL } \\
S_{f} 100-400\end{array}$ & $\begin{array}{l}\text { FCR of VLDL } \\
S_{r} 20-100^{*}\end{array}$ & \% Converted to LDLf & FCR of LDL \\
\hline & & $h^{-1}$ & $h^{-1}$ & & $d^{-1}$ \\
\hline $\mathrm{N}_{5}$ & ${ }^{125} \mathrm{I}-\mathrm{VLDL}\left(\mathrm{S}_{\mathrm{f}} 100-400\right)$ & 1.33 & 0.27 & $\begin{array}{c}38 \%(d=1.019-1.063) \\
1 \%\left(\mathrm{~S}_{\mathrm{f}} 0-12\right)\end{array}$ & 0.48 \\
\hline $\mathrm{N}_{6}$ & ${ }^{125} \mathrm{I}-\mathrm{VLDL}\left(\mathrm{S}_{\mathrm{f}} 100-400\right)$ & 0.72 & 0.33 & $\begin{array}{l}31 \%(d=1.019-1.063) \\
24 \%\left(S_{f} 0-12\right)\end{array}$ & 0.43 \\
\hline $\mathbf{N}_{7}$ & ${ }^{125} \mathrm{I}-\mathrm{VLDL}\left(\mathrm{S}_{\mathrm{f}} 100-400\right)$ & 0.40 & 0.12 & $\begin{array}{l}20 \%(d=1.019-1.063) \\
6 \%\left(S_{f} 0-12\right)\end{array}$ & 0.24 \\
\hline $\mathrm{N}_{5}$ & $\begin{array}{l}{ }^{131} \mathrm{I}-\mathrm{VLDL} \\
\quad(d<1.006 \mathrm{~kg} / \text { liter })\end{array}$ & & 0.42 & $\begin{array}{l}66 \%(d=1.019-1.063) \\
45 \%\left(S_{f} 0-12\right)\end{array}$ & 0.31 \\
\hline $\mathbf{N}_{6}$ & $\begin{array}{l}{ }^{131} \mathrm{I}-\mathrm{VLDL} \\
\quad(d<1.006 \mathrm{~kg} / \mathrm{liter})\end{array}$ & & 0.48 & $\begin{array}{l}65 \%(d=1.019-1.063) \\
35 \%\left(\mathrm{~S}_{\mathrm{r}} 0-12\right)\end{array}$ & 0.43 \\
\hline $\mathrm{N}_{7}$ & $\begin{array}{l}{ }^{131} \mathrm{I}-\mathrm{VLDL} \\
\quad(d<1.006 \mathrm{~kg} / \text { liter })\end{array}$ & & 0.57 & $\begin{array}{l}87 \%(d=1.019-1.063) \\
46 \%\left(S_{\mathrm{f}} 0-12\right)\end{array}$ & 0.31 \\
\hline
\end{tabular}

FCR, fractional catabolic rate. * Derived by computer analysis of the difference between apoB radioactivities in VLDL of $d<1.006 \mathrm{~kg} / \mathrm{liter}$ (equivalent to $\left.S_{\mathrm{f}} 20-400\right)$ and VLDL of $S_{\mathrm{f}} 100-400$. ₹ The LDL fraction was prepared in one of two ways: $(a)$ by isolation between densities 1.019 and $1.063 \mathrm{~kg} /$ liter, or $(b)$ by cumulative flotation in the $\mathrm{S}_{\mathrm{f}}$ range $0-12$, by use of system II (see Methods). 
Table V. Experiment C. Metabolism of $S_{f} 40-60$ and $S_{f}$ 20-40 Lipoproteins in Two Normal Subjects

\begin{tabular}{|c|c|c|c|c|c|c|c|c|c|}
\hline \multirow[b]{2}{*}{ Subject } & \multirow[b]{2}{*}{$\begin{array}{l}\text { Lipoprotein } \\
\text { injected }\end{array}$} & \multicolumn{6}{|c|}{ Rate constants $\left(h^{-1}\right)^{*}$} & \multirow{2}{*}{$\begin{array}{l}\text { Catabolic rate } \\
\text { from } S_{r} 12-100 \\
\text { lipoproteins }\end{array}$} & \multirow[b]{2}{*}{$\begin{array}{l}\text { \% Conversion } \\
\text { to LDL }\end{array}$} \\
\hline & & $k_{4}$ & $k_{s}$ & $k_{6}$ & $k_{7}$ & $k_{8}$ & $k_{10}$ & & \\
\hline & & & & & & & & $d^{-1}$ & \\
\hline \multirow{2}{*}{$\mathrm{N}_{8}$} & ${ }^{131} I S_{f} 40-60$ & 0.22 & 0.84 & 0 & 0.025 & 0.025 & 0.015 & 1.4 & $35 \%$ \\
\hline & ${ }^{125} \mathrm{I} \mathrm{S}_{\mathrm{f}} 20-40$ & 0.082 & 0.31 & 0 & 0.026 & 0.084 & 0.016 & 2.4 & $59 \%$ \\
\hline \multirow{2}{*}{$\mathrm{N}_{9}$} & ${ }^{131} I S_{f} 40-60$ & 0.079 & 0.16 & 0 & 0.065 & 0.12 & 0.015 & 2.9 & $43 \%$ \\
\hline & ${ }^{125} I_{S} S_{f} 20-40$ & 0.054 & 0.32 & 0 & 0.08 & 0.17 & 0.018 & 3.8 & $58 \%$ \\
\hline
\end{tabular}

* These rate constants are defined in the model shown in Fig. 3. In this study radioactive label was introduced into compartment 3, i.e., the first compartment in the intermediate lipoprotein range. The estimated rate constants describe the movement of apoB radioactivity from the entire $S_{\mathrm{f}} 12-100$ range into $S_{\mathrm{f}} 0-12$.

to show substantial variation in their physicochemical properties. It seems appropriate now to consider the likelihood that metabolic heterogeneity accompanies this structural diversity. This question is addressed in the present study.

Early metabolic investigations of the conversion of VLDL to LDL relied heavily on anglehead centrifugation for fractionation of the lipoprotein species. The results indicated that the apoB component of VLDL $(d<1.006 \mathrm{~kg} /$ liter) was transferred virtually quantitatively into the LDL density range $(d=1.006-$ $1.063 \mathrm{~kg} /$ liter) in normal subjects (1), but incompletely in hypertriglyceridemics $(2,19)$. A second generation of studies dissected out a transient intermediate in this process of nominal density $1.006-1.019 \mathrm{~kg} /$ liter, which seemed to conserve all apoB from VLDL but transmit only a fraction of it into LDL, even in normal individuals $(5,6)$. In addition, it became clear that input of apoB into the VLDL $\rightarrow$ LDL cascade could occur at multiple sites, indicating that particles of different composition were being secreted continuously into what was originally considered to be a single pool $(4,22)$. In order to calculate B protein flux rates it had to be assumed that such particles become almost instantaneously metabolically identical. However, as Fisher (22) has pointed out, this is not very likely. He raises the alternative possibility that chemical equilibrium is not reached and so metabolic channeling must occur in the cascade. The design of experiments to investigate this process must take into account the history of the population of particles used as the tracer in kinetic studies. Reardon and Steiner (3) first approached this problem by showing that not all of the intermediate lipoproteins of $S_{f} 12-100$ isolated by anglehead centrifugation derived from larger triglyceride-rich $S_{\mathrm{f}} 100-400$ particles. The implication here was that these two synthetic sites produce particles not only of different size and composition but also with different metabolic potential. Lipoprotein lipase, the key enzyme involved in VLDL lipolysis,

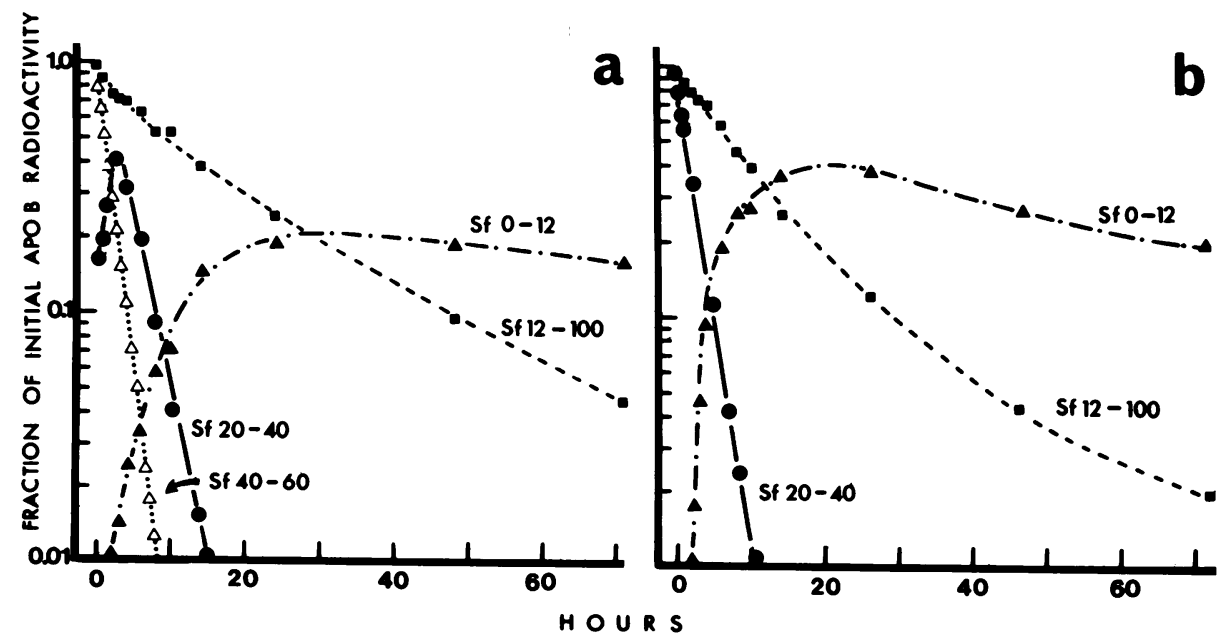

Figure 6. Metabolic fate of apoB in $\mathrm{S}_{\mathrm{f}}$ 20-40 and 40-60 lipoproteins in subject $\mathrm{N}_{8}$. The above fractions were prepared and labeled with ${ }^{125} \mathrm{I}$ and ${ }^{131} \mathrm{I}$, respectively. The subsequent transit of their apoB from $S_{f} 12-100$ to $S_{f} 0-12$ is shown above. The flow of $B$ protein radioactivity through $S_{\mathrm{f}} 40-60$ and 20 40 particles is also included. (a) Decay curves obtained after injection of $S_{f} 40$ 60 particles. $(b)$ Decay curves after injection of $S_{\mathrm{f}} 20-40$ particles. 


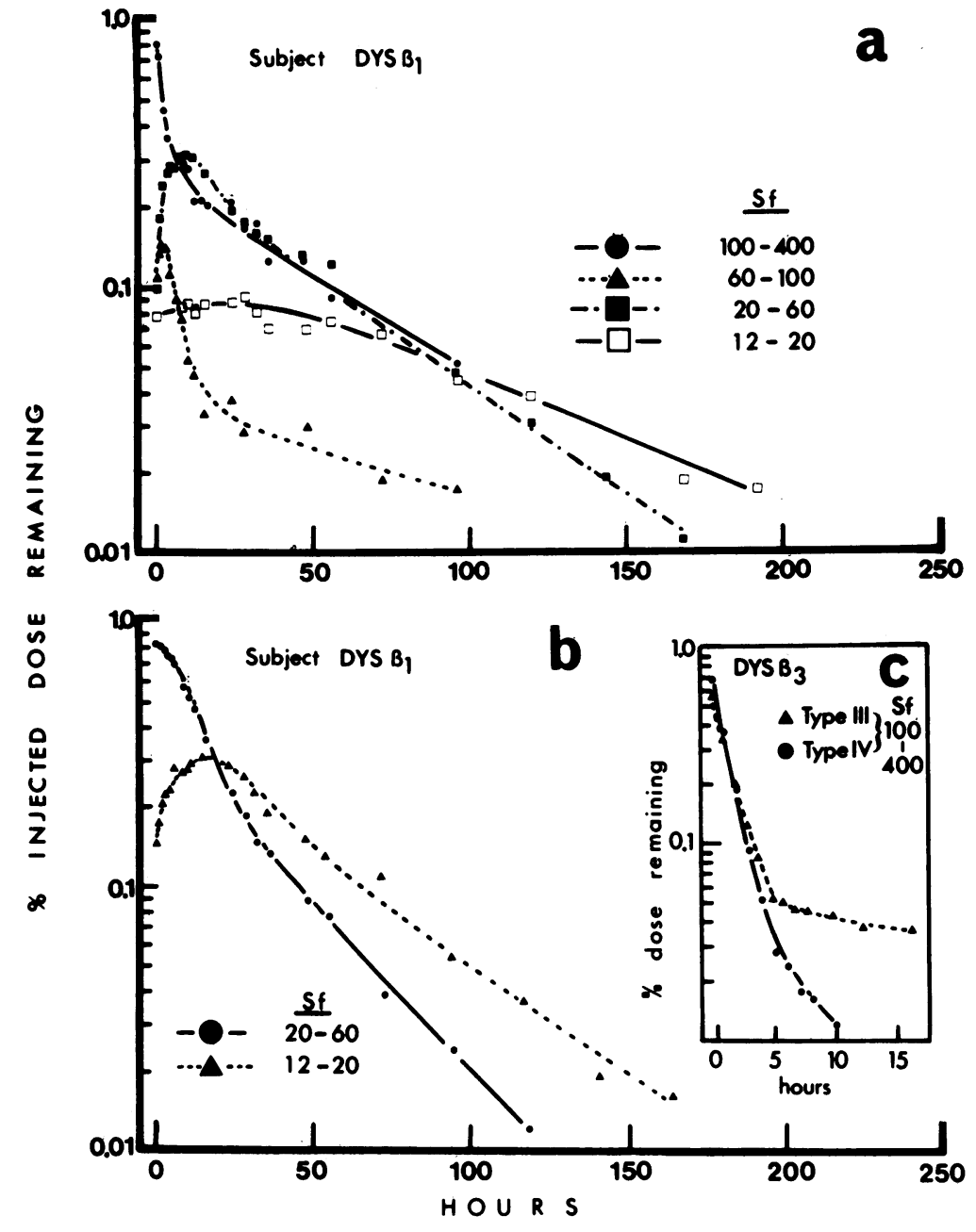

Figure 7. The metabolic decay of apoB in VLDL of $S_{f}$ $100-400$ and $20-60$ in dysbetalipoproteinemia. $a$ describes in subject Dys $\beta_{1}$ the transfer of apoB radioactivity from $S_{\mathrm{f}} 100-400$ particles through $\mathrm{S}_{\mathrm{f}} 60-100$ and 20-60 to 12-20. In $b, \mathrm{~S}_{\mathrm{f}}$ 20-60 lipoproteins were isolated directly and radiolabeled before reinjection. The decay of apoB activity from this fraction into particles of $S_{f} 12-20$ is shown. $c$ compares the clearance of apoB from the $S_{f}$ 100-400 range when autologous material and homologous VLDL from subject HTG $_{5}$ were injected into subject $\mathrm{Dys} \beta_{3}$. may be able to distinguish between newly secreted $S_{\mathrm{f}} 12-100$ particles and partially delipidated $S_{\mathrm{f}} 100-400$ lipoproteins that have fallen into the $S_{\mathrm{f}} 12-100$ range. The present work suggests that this is the case.

The investigation of metabolic heterogeneity among lipoproteins is critically dependent on the ability of the chosen fractionation procedure to separate particles with defined physicochemical properties. The cumulative flotation procedure described by Lindgren et al. (9) offers such a possibility. Manipulation of the centrifugal conditions permits selection at will of clearly delineated lipoprotein fractions. This therefore offers significant advantages over the anglehead ultracentrifugation procedure. In experiment $B$ we found that the amount of apoB radioactivity that appeared in what was nominally LDL depended on the choice of centrifugation procedure. Fig. 9 exemplifies the point. Here we examine the transfer of radioactivity from VLDL apoB of $d<1.006 \mathrm{~kg} /$ liter into LDL prepared $(a)$ as 1.019-1.063 kg/liter lipoprotein by anglehead separation, or $(b)$ as the $\mathrm{S}_{\mathrm{f}}$ 0-12 fraction by cumulative flotation. Both of these procedures, in theory, should isolate the same LDL fraction. However, it is clear that the anglehead technique results in a higher apparent conversion than the cumulative flotation approach (Table IV). We believe that the standard conditions applied to the anglehead separation (i.e., $40,000 \mathrm{rpm}$ in a 40.3 rotor for up to $24 \mathrm{~h}[5,6]$ ) inadequately clear all lipoproteins of $S_{\mathrm{f}}>12$ from LDL in the infranatant. This proposal is supported by the observation that increasing the solute density in the anglehead rotor to $1.025 \mathrm{~kg} /$ liter (23) reduces the transfer of radioactivity into LDL towards the value obtained by cumulative flotation (Fig. 9). In three separate reports $(23-25)$ it has been observed that LDL $(d=1.019-1.063 \mathrm{~kg} /$ liter $)$ isolated in the anglehead rotor under the conditions described above was contaminated with intermediate lipoprotein of $d<1.020 \mathrm{~kg} /$ liter which could be 


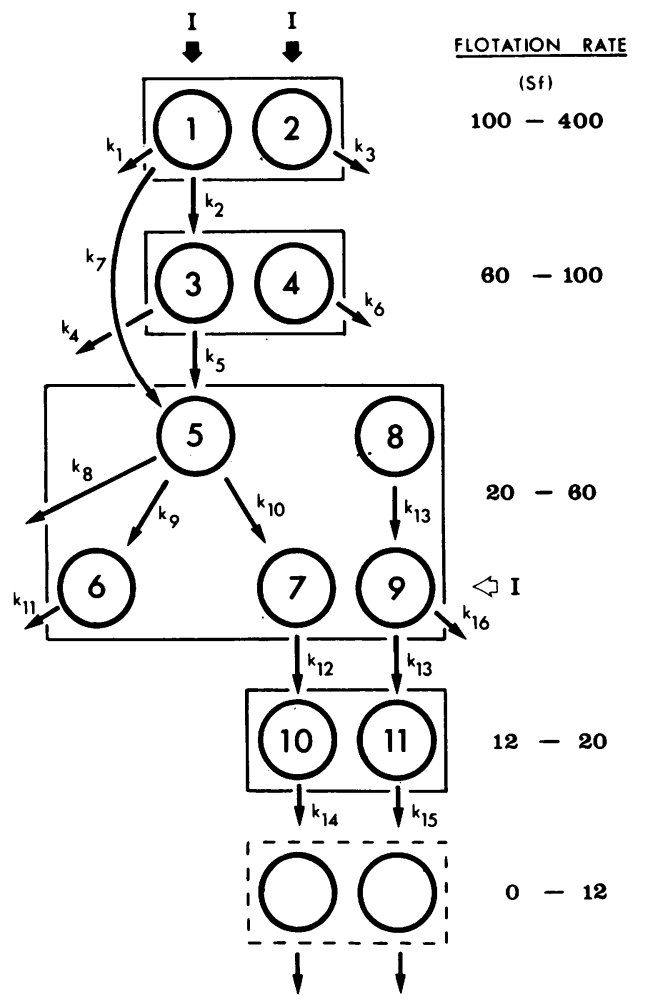

Figure 8. Multicompartmental model used to analyze the decay data shown in Fig. 7. Essentially there are two channels in the model. When VLDL $S_{\mathrm{f}} 100-400$ was injected, compartments 1 and 2 were primarily labeled. Radioactivity was distributed between these according to the two exponentials present in the decay curve of this material. Injection of $S_{f} 20-60$ primarily channeled radioactivity into the compartments in the $S_{\mathrm{f}} 20-60$ range. The dotted compartment represents the possibility that the channeling continues into the LDL $\left(\mathrm{S}_{\mathrm{f}} 0-12\right)$ density range.

eliminated by employing a more rigorous fractionation procedure. In fact, the hydrated density of lipoproteins whose flotation rate is just above the $S_{\mathrm{f}} 12$ limit for LDL is so close to that of the background $1.019 \mathrm{~kg} /$ liter density solution that several days of centrifugation in the anglehead rotor would be required to eliminate them from the LDL fraction.

In experiment $A$ we determined the metabolic fate of $S_{f}$ 100-400 VLDL apoB in normal and hypertriglyceridemic subjects by use of cumulative flotation ultracentrifugation. The large VLDL contained B protein, which in the normal subjects was transferred virtually quantitatively into intermediate lipoprotein of $S_{\mathrm{f}} 12-100$. Their subsequent catabolism was biphasic, suggesting the presence of two metabolically distinct components. Less than $10 \%$ of this material ended up in LDL. Most was cleared directly from the plasma. So, in these individuals it seems that large VLDL is not quantitatively transferred to
LDL. In the Type IV hyperlipoproteinemic subjects the pattern was essentially the same despite the fact that their VLDL pool was substantially expanded and clearance of apoB from the $S_{f}$ 100-400 density interval was retarded.

Experiment $B$ shows that in normal subjects the apoB in LDL comes mostly from small VLDL which are excluded from the $S_{\mathrm{f}}$ 100-400 fraction but are heavily iodinated when lipoproteins of $d<1.006 \mathrm{~kg} /$ liter are used. This is consistent with the fact that the efficiency of labeling of small protein-rich VLDL is much higher than that of large particles. By implication, therefore, when the anglehead ultracentrifuge rotor is used to isolate lipoproteins of $d<1.006 \mathrm{~kg} /$ liter one is in effect preparing a tracer of small VLDL. Calculation of apoB flux rates as the product of the total VLDL apoB pool $(d<1.006 \mathrm{~kg} /$ liter $)$ and its fractional clearance rate results in values for the transfer to LDL that are sufficient to account entirely for its synthesis (Table III) in agreement with earlier published data $(1,2,6,19)$. However, as indicated above, this ignores the problem of metabolic channeling. The true flux rates can only be determined from a knowledge of the size and catabolic rate of the individual apoB subcompartments in VLDL.

In experiment $\mathrm{C}$ we attempted to examine more closely the particle distribution in the VLDL subcompartments. We predicted that VLDL of $S_{f} 40-60$ would probably be enriched in lipoproteins derived by catabolism of large triglyceride-rich particles $\left(S_{\mathrm{f}} 100-400\right)$ whereas direct particle synthesis into the $\mathrm{S}_{\mathrm{f}}$ 12-100 range would favor the smaller VLDL $\left(\mathrm{S}_{\mathrm{f}} 20-40\right)$. If this assumption is correct, on the basis of the previous argument, the $S_{\mathrm{f}}$ 20-40 lipoproteins should transit more rapidly and completely into LDL than would the larger $S_{f} 40-60$ particles. Fig. 6 shows that our prediction was correct. So, even these VLDL particles with similar flotation rates are substantially different in their metabolic behavior. However, it must be remembered that particles of $S_{\mathrm{f}} 20$ (diameter $\sim 300 \AA$ ) have only one third $(10,11)$ of the volume of $S_{f} 60$ particles (diameter $450 \AA$ ). This size difference allows for substantial underlying structural variability to account for the observed metabolic heterogeneity.

In the final series of studies (experiment D) we followed apoB metabolism in Type III hyperlipoproteinemic subjects in an attempt to locate more accurately the lesion in apoB metabolism that accompanies this phenotype. We found that the conversion of large VLDL $\left(S_{\mathrm{f}} 100-400\right)$ to smaller particles in the $S_{f}$ 20-60 flotation range was normal. This is consonant with the knowledge that lipoprotein lipase levels in Type III hyperlipoproteinemic subjects are normal (26). Only when the VLDL apoB reached the intermediate density range $\left(S_{\mathrm{f}}<60\right)$ was its further catabolic progress retarded. However, it should be noted that the $S_{\mathrm{f}} 100-400$ VLDL fraction in the subjects did contain substantial amounts of $B$ protein whose catabolism was very slow. The only other subjects who demonstrate 
Table VI. Experiment D. Metabolism of $S_{f} 100-400$ and $S_{f} 20-60$ VLDL apoB in Three Dysbetalipoproteinemic and a Hypertriglyceridemic Subject

\begin{tabular}{|c|c|c|c|c|c|c|c|c|c|}
\hline \multirow[b]{2}{*}{ Subject } & \multirow[b]{2}{*}{ Tracer } & \multicolumn{8}{|c|}{ Rate constants" $\left(h^{-1}\right)$} \\
\hline & & $k_{1}$ & $k_{2}$ & $k_{3}$ & $k_{4}$ & $k_{s}$ & $k_{6}$ & $k_{7}$ & $k_{8}$ \\
\hline Dys $\beta_{1}$ & $\begin{array}{l}{ }^{131} \mathrm{I}-\mathrm{VLDL}\left(\mathrm{S}_{\mathrm{f}} 100-400\right) \\
{ }^{125} \mathrm{I}-\mathrm{VLDL}\left(\mathrm{S}_{\mathrm{f}} 20-60\right)\end{array}$ & 0.23 & 0.14 & 0.018 & 0.009 & 0.31 & 0.019 & 0.11 & 0.016 \\
\hline Dys $\beta_{2}$ & $\begin{array}{l}{ }^{131} \mathrm{I}-\mathrm{VLDL}\left(\mathrm{S}_{\mathrm{f}} 100-400\right) \\
{ }^{125} \mathrm{I}-\mathrm{VLDL}\left(\mathrm{S}_{\mathrm{f}} 20-60\right)\end{array}$ & 0.0 & 0.26 & 0.024 & 0.0 & 0.20 & 0.017 & 0.15 & 0.007 \\
\hline Dys $\beta_{3}$ & $\begin{array}{l}{ }^{131} \text { I-VLDL }\left(S_{f} 100-400\right) \\
\quad\left(H_{T} G_{5}\right)\end{array}$ & 0.27 & 0.23 & 0.08 & 0.0 & 0.22 & 0.0 & 0.13 & 0.048 \\
\hline & $\begin{array}{l}{ }^{125} \text { I-VLDL }\left(S_{f} 100-400\right) \\
\left(D y s \beta_{3}\right)\end{array}$ & 0.27 & 0.40 & 0.037 & 0.005 & 0.35 & 0.018 & 0.017 & 0.021 \\
\hline HTG $_{5}$ & $\begin{array}{l}{ }^{131} \mathrm{I}-\mathrm{VLDL}\left(\mathrm{S}_{\mathrm{f}} 100-400\right) \\
{ }^{125} \mathrm{I}-\mathrm{VLDL}\left(\mathrm{S}_{\mathrm{f}} 20-60\right)\end{array}$ & 0.0 & 0.13 & 0.0 & 0.11 & 0.073 & 0.045 & 0.0 & 0.0 \\
\hline
\end{tabular}

* The rate constants are defined in Fig. 8. ‡ Fractional catabolic rate of the rapid VLDL $S_{f} 100-400$ component $=k_{1}+k_{2}+k_{7}$ (Fig. 8). $\S$ Fractional catabolic rate of $S_{f} 20-60$ apoB radioactivity derived from $S_{f} 100-400$ VLDL. "Fractional catabolic rate of directly labeled VLDL of $S_{f} 20-60$.

similar biphasic $S_{\mathrm{f}} 100-400$ lipoprotein catabolism are hyperchylomicronemic individuals with the Type $\mathrm{V}$ phenotype (see reference 20 ). We favor the possibility that the slowly metabolized apoB species is located in chylomicron remnants. Meng and coworkers (27) have shown recently that $\mathrm{apoB}_{48}$, a marker of chylomicrons, occurs in significant amounts only in the total VLDL fraction of Type III and Type V hyperlipoproteinemic individuals; and Nestel et al. (28) have shown that in Type V subjects, apo $_{48}$ is removed more slowly from the plasma than is $a p o B_{100}$. So it is not surprising that the $S_{\mathbf{f}} 100$ 400 VLDL from a Type IV subject, who does not accumulate chylomicrons or their remnants, is catabolized virtually monoexponentially when injected into subject Dys $\beta_{3}$ (Fig. $7 c$ ). Although these putative chylomicron remnants accumulate in Type III plasma, they are not the only slowly metabolized species in the $S_{f}>20$ VLDL. ApoB that has transferred in an apparently normal way from larger triglyceride-rich VLDL lingers in the $S_{\mathrm{f}}$ 20-60 range, suggesting that further processing

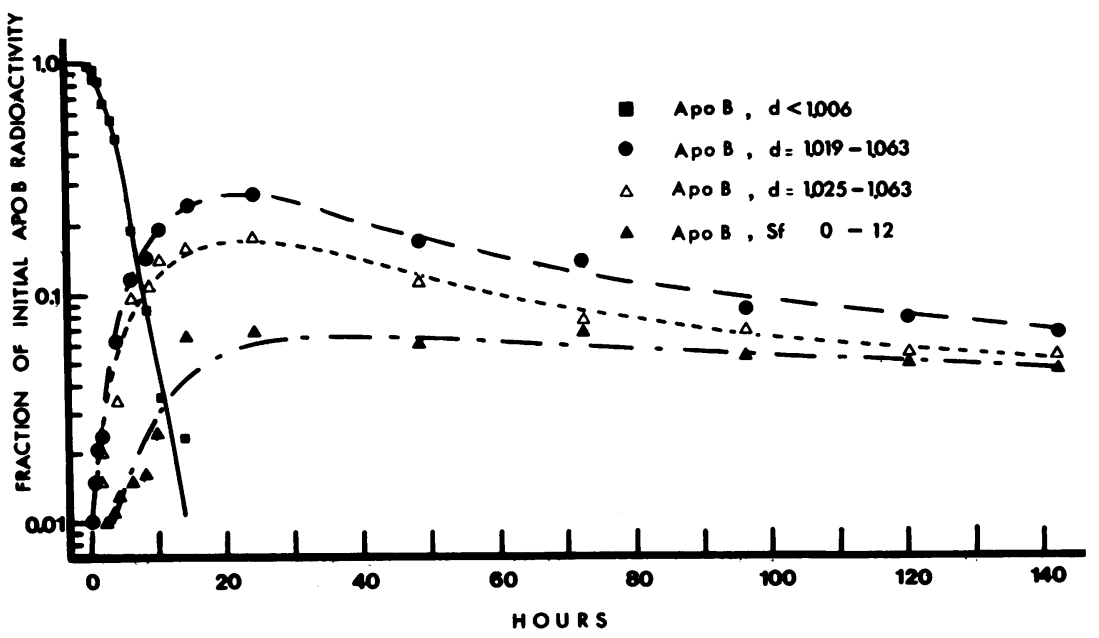

Figure 9. The disappearance of apoB radioactivity injected in $S_{\mathbf{f}} 100-400$ VLDL and reisolated from the $d<1.006 \mathrm{~kg} /$ liter density interval. The appearance of this radioactivity in the intervals $1.019-1.063$ and $1.025-1.063 \mathrm{~kg} /$ liter and $\mathrm{S}_{\mathrm{f}} 0-12$ is shown above. The data here are from subject $\mathrm{N}_{7}$. Note that for the sake of clarity the curve representing apoB radioactivity in $\mathrm{S}_{\mathbf{f}} \mathbf{1 2 - 2 0}$ lipoproteins has been omitted from the figure. 


\begin{tabular}{|c|c|c|c|c|c|c|c|c|c|c|}
\hline \multirow[b]{3}{*}{$k_{9}$} & \multirow[b]{3}{*}{$k_{10}$} & \multirow[b]{3}{*}{$k_{11}$} & \multirow[b]{3}{*}{$k_{12}$} & \multirow[b]{3}{*}{$k_{13}$} & \multirow[b]{3}{*}{$k_{14}$} & \multirow[b]{3}{*}{$k_{15}$} & \multirow[b]{3}{*}{$k_{16}$} & \multicolumn{3}{|c|}{ Fractional catabolic rate $\left(h^{-1}\right)$} \\
\hline & & & & & & & & \multirow{2}{*}{$\begin{array}{l}S_{\mathrm{Y}} 100-400 \ddagger \\
\text { VLDL } \\
\text { apoB }\end{array}$} & \multirow{2}{*}{$\begin{array}{l}S_{1} 20-608 \\
\text { VLDL } \\
\text { apoB }\end{array}$} & \multirow{2}{*}{$\begin{array}{l}S_{1} 20-60^{\prime \prime} \\
\text { VLDL } \\
\text { apoB }\end{array}$} \\
\hline & & & & & & & & & & \\
\hline \multirow[t]{2}{*}{0.19} & 0.30 & 0.11 & 0.017 & - & 0.032 & - & - & 0.48 & 0.025 & \\
\hline & & 0.0 & 0.026 & 0.11 & 0.028 & 0.09 & 0.018 & & & 0.069 \\
\hline \multirow[t]{2}{*}{0.062} & 0.049 & 0.025 & 0.02 & - & 0.027 & - & - & 0.41 & 0.020 & \\
\hline & & 0.015 & 0.015 & 0.06 & 0.036 & 0.071 & 0.0 & & & 0.048 \\
\hline 0.076 & 0.037 & 0.016 & 0.22 & - & 0.12 & - & - & 0.67 & 0.025 & \\
\hline 0.071 & 0.11 & 0.009 & 0.043 & - & 0.012 & - & - & 0.72 & 0.018 & \\
\hline \multirow[t]{2}{*}{0.27} & 0.33 & 0.025 & 0.098 & - & 0.022 & - & - & 0.13 & 0.040 & \\
\hline & & 0.018 & 0.018 & 0.15 & 0.020 & 0.072 & 0.034 & & & 0.164 \\
\hline
\end{tabular}

of these VLDL remnants is blocked by the metabolic defect. But these remnants apparently constitute only a fraction of the $S_{\mathrm{f}}$ 20-60 lipoproteins. When the latter are isolated and labeled directly, most exhibit relatively rapid plasma clearance into particles of $\mathrm{S}_{\mathrm{f}} 12-20$ (Fig. $7 \mathrm{~b}$ ). These individuals therefore also seem to have at least two metabolically distinct small VLDL particle types.

The weight of evidence presented in this study suggests that chemical equilibrium and therefore metabolic homogeneity is not a feature of VLDL turnover. The ultimate fate of any particular particle depends on its pedigree. In both normal and hypertriglyceridemic subjects there appear to be within

Table VII. Experiment D. Plasma Concentrations of apoB in $S_{f} 12-400$ Subfractions

\begin{tabular}{|c|c|c|c|c|}
\hline \multirow[b]{2}{*}{ Subject } & \multicolumn{4}{|c|}{ Plasma apoB concentrations $(\mathrm{mg} / \mathrm{dl})^{*}$} \\
\hline & $S_{r}, 100-400$ & S $60-100$ & $S_{r} 20-60$ & S, $12-20$ \\
\hline Dys $\beta_{1}$ & 1.9 & 2.6 & 15.7 & 13.3 \\
\hline Dys $\beta_{2}$ & 2.0 & 4.7 & 26.7 & 19.8 \\
\hline Dys $\beta_{3}$ & 0.76 & 2.0 & 15.2 & 19.1 \\
\hline $\mathrm{HTG}_{5}$ & 5.0 & 8.0 & 12.7 & 15.9 \\
\hline
\end{tabular}

* Determined as the tetramethylurea precipitable protein present in subfractions taken from fasting plasma samples $(n=14)$. the small VLDL density range at least two distinct particle types. One, a remnant of large triglyceride-rich VLDL, is catabolized slowly within the $S_{\mathrm{f}} 12-100$ flotation interval and is not significantly transferred to LDL. The other, synthesized directly as small VLDL, is rapidly converted into LDL and constitutes its major precursor.

\section{Acknowledgments}

Annette Fox provided excellent secretarial assistance.

The work described here was supported by grants from the Medical Research Council (G 8111558 SA) and the Scottish Home and Health Department.

\section{References}

1. Sigurdsson, G., A. Nicoll, and B. Lewis. 1975. Conversion of very low density lipoprotein to low density lipoprotein. J. Clin. Invest. 56:1481-1490.

2. Reardon, M. F., N. H. Fidge, and P. J. Nestel. 1978. Catabolism of very low density lipoprotein in man. J. Clin. Invest. 61:850-860.

3. Reardon, M. F., and G. Steiner. 1982. The use of kinetics in investigating the metabolism of very low and intermediate density lipoproteins. In Lipoprotein Kinetics and Modeling. M. Berman, S. M. Grundy, and B. V. Howard, editors. Academic Press, New York. 99-112. 
4. Fisher, W. R., L. A. Zech, P. Bardalaye, G. Warmke, and M. Berman. 1980. The metabolism of apolipoprotein B in subjects with hypertriglyceridemia and polydisperse LDL. J. Lipid Res. 21:760-774.

5. Berman, M., M. Hall, R. I. Levy, S. Eisenberg, D. W. Bilheimer, R. D. Phair, and R. H. Goebel. 1978. Metabolism of apoB and apoC lipoproteins in man: kinetic studies in normal and hyperlipoproteinemic subjects. J. Lipid Res. 19:38-56.

6. Janus, E. D., A. Nicoll, R. Wootton, P. R. Turner, P. J. Magill, and B. Lewis. 1980. Quantitative studies of very low density lipoprotein conversion to low density lipoprotein in normal controls and primary hyperlipidemic states and the role of direct secretion of low density lipoprotein in heterozygous familial hypercholesterolemia. Eur. J. Clin. Invest. 10:149-160.

7. Sata, T., R. J. Havel, and A. L. Jones. 1972. Characterization of subfractions of triglyceride-rich lipoproteins separated by gel chromatography from blood plasma of normolipemic and hyperlipemic humans. J. Lipid Res. 13:757-768.

8. Mjos, O. D., O. Faergeman, R. L. Hamilton, and R. J. Havel. 1975. Characterization of remnants produced during the metabolism of triglyceride rich lipoproteins of blood plasma and intestinal lymph in rat. J. Clin. Invest. 56:603-615.

9. Lindgren, F. T., L. C. Jensen, and F. T. Hatch. 1972. The isolation and quantitative analysis of serum lipoproteins. In Blood Lipids and Lipoproteins: Quantitation, Composition and Metabolism. G. J. Nelson, editor. John Wiley \& Sons, New York. 181-274.

10. Kane, J. P., T. Sata, R. L. Hamilton, and R. J. Havel. 1975. Apoprotein composition of very low density lipoproteins of human serum. J. Clin. Invest. 56:1622-1634.

11. Packard, C. J., J. Shepherd, S. Joerns, A. M. Gotto, and O. D. Taunton. 1979. Very low density and low density lipoprotein subfractions in Type III and Type IV hyperlipoproteinemia. Biochim. Biophys. Acta. 572:269-282.

12. Packard, C. J., J. Shepherd, A. M. Gotto, and O. D. Taunton. 1977. Kinetic analysis of very low density lipoprotein subfractions in Type III and IV hyperlipoproteinemia. Clin. Res. 25:396A. (Abstr.)

13. Lipid Research Clinics Program Manual of Laboratory Operations. 1975. Department of Health, Education, and Welfare Publication 75-268. National Institutes of Health, Bethesda, MD.

14. Havel, R. J., H. A. Eder, and J. H. Bragdon. 1955. The distribution and chemical composition of ultracentrifugally separated lipoproteins in human serum. J. Clin. Invest. 34:1345-1353.

15. Bilheimer, D. W., S. Eisenberg, and R. I. Levy. 1972. The metabolism of very low density lipoprotein proteins. I. Preliminary in vitro and in vivo observations. Biochim. Biophys. Acta. 26:212-221.

16. MacFarlane, A. S. 1958. Efficient trace labeling of proteins with iodine. Nature (Lond.). 182:53.

17. Kane, J. P., D. A. Hardman, and H. E. Paulus. 1980. Heterogeneity of apolipoprotein B: isolation of a new species from human chylomicrons. Proc. Natl. Acad. Sci. USA. 77:2465-2469.
18. Holmqvist, L., K. Carlson, and L. A. Carlson. 1978. Comparison between the use of isopropanol and tetramethylurea for the solubilization and quantitation of human serum very low density apolipoproteins. Anal. Biochem. 88:457-460.

19. C. J. Packard, J. Shepherd, S. Joerns, A. M. Gotto, and O. D. Taunton. 1980. Apolipoprotein B metabolism in normal, Type IV and Type V hyperlipoproteinemic subjects. Metab. Clin. Exp. 29:213-222.

20. Shepherd, J., C. J. Packard, J. M. Stewart, R. F. Atmeh, R. S. Clark, D. E. Boag, K. Carr, A. R. Lorimer, D. Ballantyne, H. G. Morgan, and T. D. V. Lawrie. 1984. Apolipoprotein A and B ( $S_{\mathrm{f}} 100$ 400) metabolism during bezafibrate therapy in hypertriglyceridemic subjects. J. Clin. Invest. 74:2164-2177.

21. Morganroth, J., R. I. Levy, and D. S. Fredrickson. 1975. The biochemical, clinical and genetic features of Type III hyperlipoproteinemia. Ann. Intern. Med. 82:158-168.

22. Fisher, W. R. 1982. Apoprotein B kinetics in man: concepts and questions. In Lipoprotein Kinetics and Modeling. M. Berman, S. M. Grundy, and B. V. Howard, editors. Academic Press, New York. 43-68.

23. Patsch, J. R., S. Sailer, and H: Braunsteiner. 1975. Lipoprotein of the density 1.006-1.020 in the plasma of patients with Type III hyperlipoproteinemia in the postabsorptive state. Eur. J. Clin. Invest. 5:45-55.

24. Shen, M. S., R. M. Krauss, F. T. Lindgren, and T. M. Forte. 1981. Hetrogeneity of serum low density lipoproteins in normal human subjects. J. Lipid Res. 22:236-244.

25. Krauss, R. M., and D. J. Burke. 1982. Identification of multiple subclasses of plasma low density lipoproteins in normal humans. $J$. Lipid Res. 23:97-104.

26. Krauss, R. M., R. I. Levy, and D. S. Fredrickson. 1974. Selective measurement of two lipase activities in postheparin plasma from normal subjects and patients with hyperlipoproteinemia. J. Clin. Invest. 54:1107-1124.

27. Meng, M. S., R. E. Gregg, E. J. Schaefer, J. M. Hoeg, and H. B. Brewer. 1983. Presence of two forms of apolipoprotein B in patients with dyslipoproteinemia. J. Lipid Res. 24:803-809.

28. Nestel, P. J., T. Billington, and N. H. Fidge. 1983. Slower removal of intestinal apolipoprotein B48 than of apolipoprotein B100 in severely hypertriglyceridemic subjects. Biochim. Biophys. Acta. 751:422-427.

29. Berman, M., and M. F. Weiss. 1974. SAAM Manual. U. S. Public Health Service Publication 1703. U. S. Government Printing Office, Washington DC.

30. Metzler, C. M., G. L. Elfring, and A. J. McEwan. 1974. A package of computer programs for pharmacokinetic modeling. Biometrics. 30:569-582.

31. Berman, M. 1963. The formulation and testing of models. Ann. NY Acad. Sci. 108:182-194. 